RESEARCH SERIES

NUMBER 124

APRIL 2021

\section{REVIEW OF INTERNATIONAL APPROACHES TO EVALUATING RURAL AND COMMUNITY DEVELOPMENT INVESTMENT AND SUPPORTS}

\section{ADELE WHELAN, SEAMUS MCGUINNESS AND ALAN BARRETT}

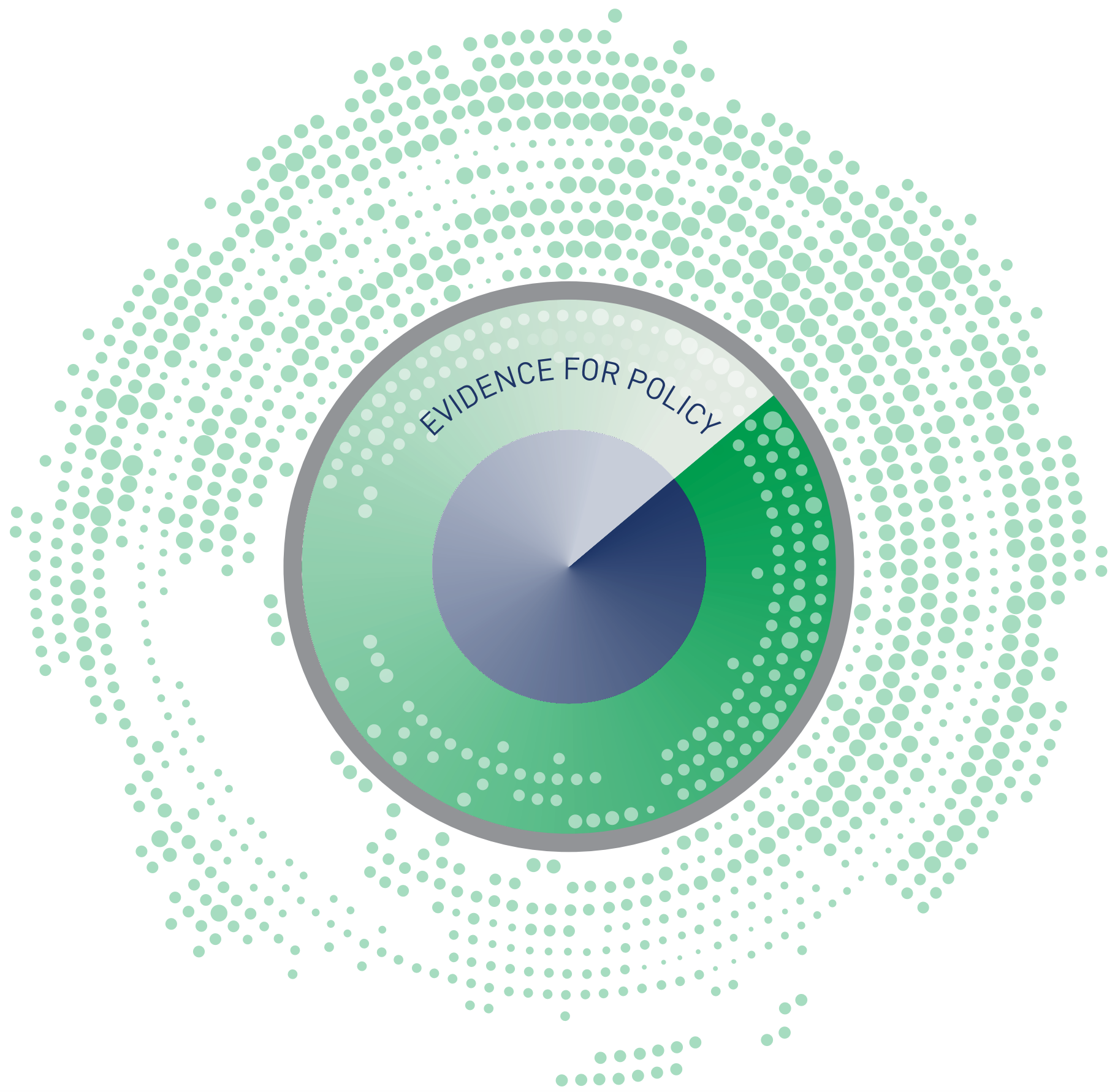




\section{REVIEW OF INTERNATIONAL APPROACHES \\ TO EVALUATING RURAL AND COMMUNITY \\ DEVELOPMENT INVESTMENT AND SUPPORTS}

Adele Whelan

Seamus McGuinness

Alan Barrett

April 2021

\section{RESEARCH SERIES}

\section{NUMBER 124}

Available to download from www.esri.ie

(C) The Economic and Social Research Institute

Whitaker Square, Sir John Rogerson's Quay, Dublin 2

https://doi.org/10.26504/rs124

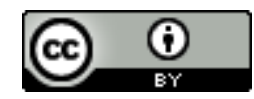

This Open Access work is licensed under a Creative Commons Attribution 4.0 International License (https://creativecommons.org/licenses/by/4.0/), which permits unrestricted use, distribution, and reproduction in any medium, provided the original work is properly credited. 


\section{ABOUT THE ESRI}

The mission of the Economic and Social Research Institute is to advance evidencebased policymaking that supports economic sustainability and social progress in Ireland. ESRI researchers apply the highest standards of academic excellence to challenges facing policymakers, focusing on 12 areas of critical importance to 21st Century Ireland.

The Institute was founded in 1960 by a group of senior civil servants led by $\mathrm{Dr}$ T. K. Whitaker, who identified the need for independent and in-depth research analysis to provide a robust evidence base for policymaking in Ireland.

Since then, the Institute has remained committed to independent research and its work is free of any expressed ideology or political position. The Institute publishes all research reaching the appropriate academic standard, irrespective of its findings or who funds the research.

The quality of its research output is guaranteed by a rigorous peer review process. ESRI researchers are experts in their fields and are committed to producing work that meets the highest academic standards and practices.

The work of the Institute is disseminated widely in books, journal articles and reports. ESRI publications are available to download, free of charge, from its website. Additionally, ESRI staff communicate research findings at regular conferences and seminars.

The ESRI is a company limited by guarantee, answerable to its members and governed by a Council, comprising 14 members who represent a cross-section of ESRI members from academia, civil services, state agencies, businesses and civil society. The Institute receives an annual grant-in-aid from the Department of Public Expenditure and Reform to support the scientific and public interest elements of the Institute's activities; the grant accounted for an average of 30 per cent of the Institute's income over the lifetime of the last Research Strategy. The remaining funding comes from research programmes supported by government departments and agencies, public bodies and competitive research programmes.

Further information is available at www.esri.ie 


\section{THE AUTHORS}

Adele Whelan is a Research Officer, Seamus McGuinness is a Research Professor, and Alan Barrett is a Research Professor at the Economic and Social Research Institute (ESRI). All members of the research team have adjunct research positions at Trinity College Dublin (TCD).

\section{ACKNOWLEDGEMENTS}

The work carried out in this report was funded by the Department of Rural and Community Development (DRCD) as part of the Joint Research Programme between the ESRI and DRCD. Valuable contributions were made by members of the Research Programme Steering Committee: Jason Cleary, Sean Duffy, Kenneth Jordan, and Sheenagh Rooney. We are extremely grateful to the members of the Research Programme Steering Committee for their ongoing support and feedback on the research. We would like to thank all the individuals within DRCD who provided assistance during the project, particularly members of the DRCD's internal evaluation sub-group and those who provided data relating to programme funding allocations. Finally, our thanks go to an external referee and two internal ESRI referees for their comments on earlier drafts of this report.

This report has been accepted for publication by the Institute, which does not itself take institutional policy positions. All ESRI Research Series reports are peer reviewed prior to publication. The authors are solely responsible for the content and the views expressed. 



\section{TABLE OF CONTENTS}

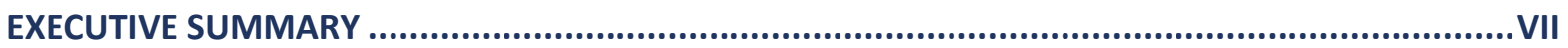

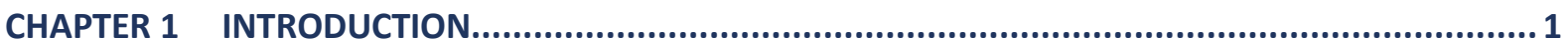

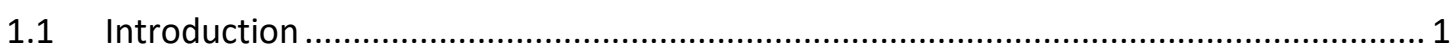

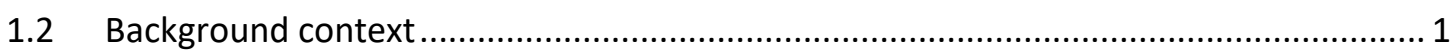

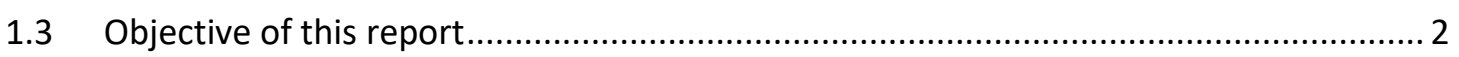

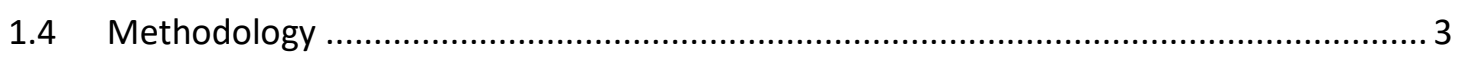

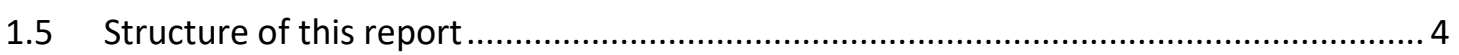

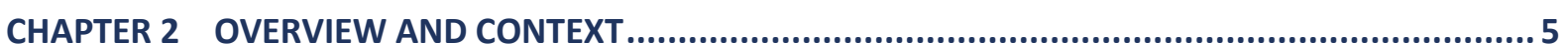

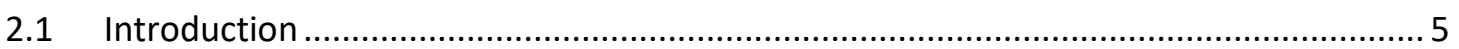

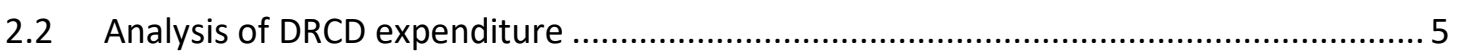

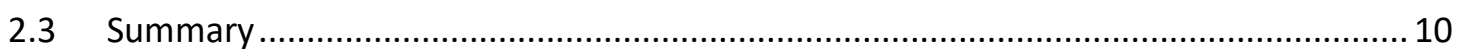

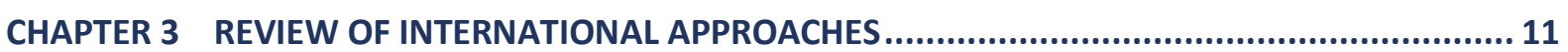

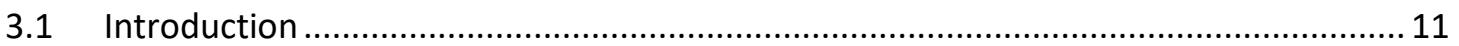

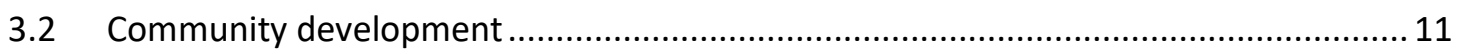

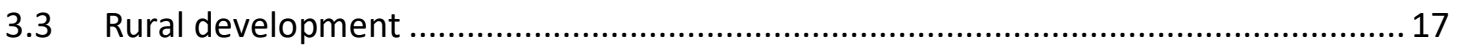

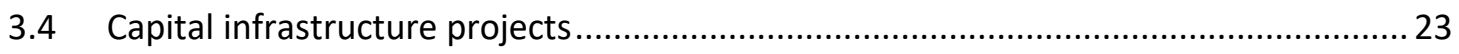

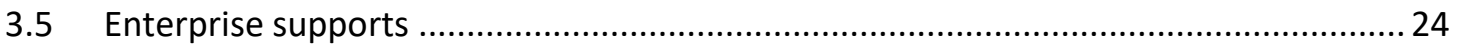

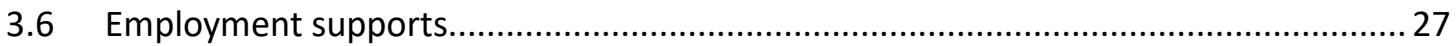

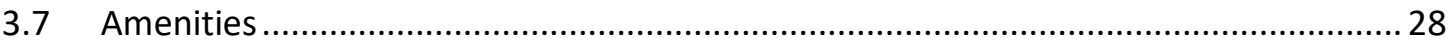

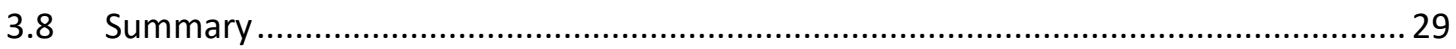

CHAPTER 4 EVALUATION APPROACHES IN THE IRISH CONTEXT ........................................... 31

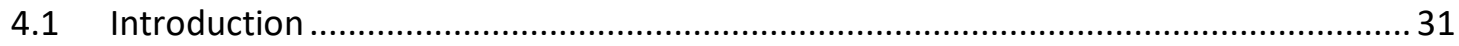

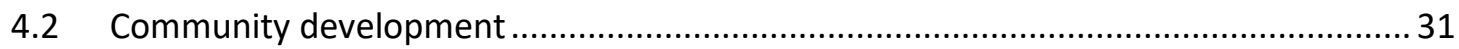

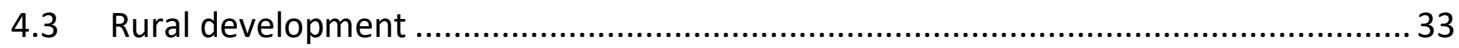

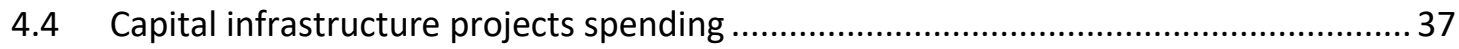

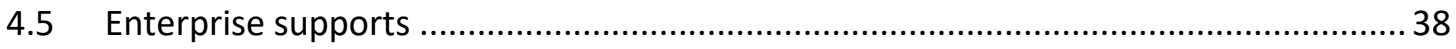

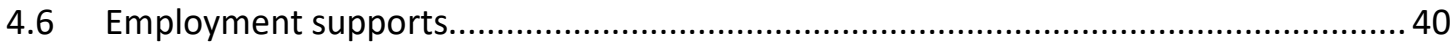

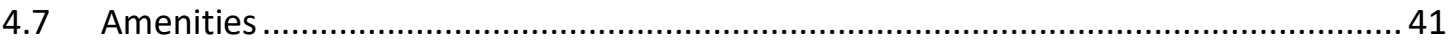

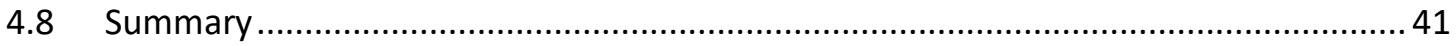




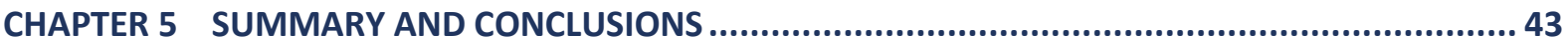

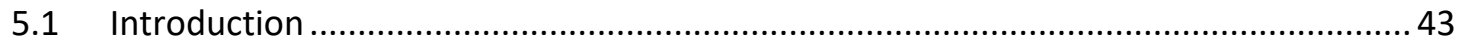

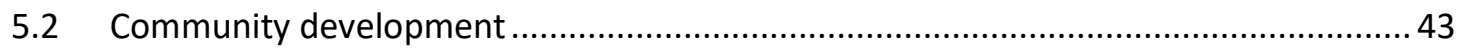

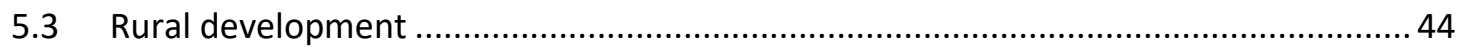

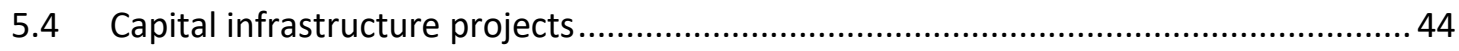

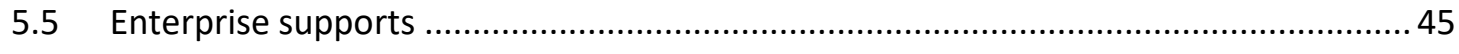

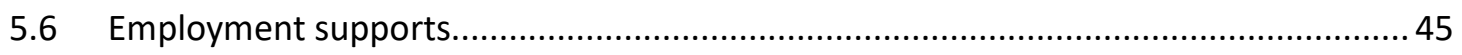

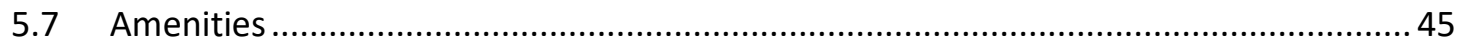

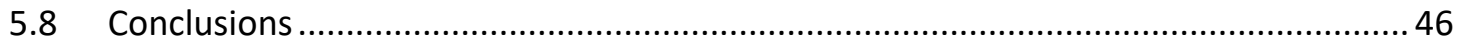

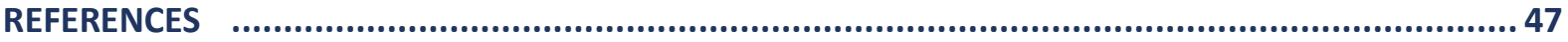

APPENDIX A

APPENDIX B ECONOMETRIC APPROACHES TO THE EVALUATION OF RURAL DEVELOPMENT

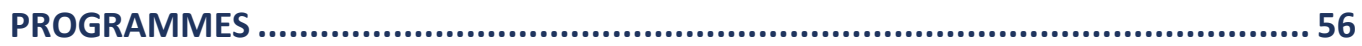

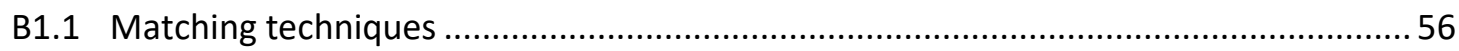

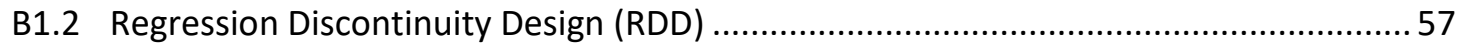

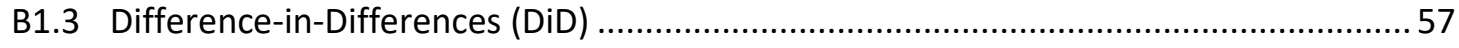

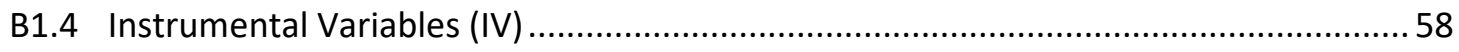




\section{LIST OF TABLES}

Table 2.1 Overview of DRCD programme expenditure in 2019 across eight broad areas............9

Table 3.1 Programme action and Logic Model example ......................................................... 12

Table 4.1 CSO six-way urban/rural categorisation, 2019 .......................................................... 36

Table A.1 Logic Model example for SICAP (Goal 1) …….......................................................... 55

Table B.1 Overview of the methodological approaches, types of bias addressed and data

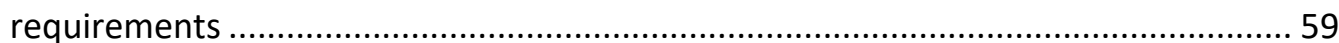

\section{LIST OF FIGURES}

Figure 2.1 Rural development and regional affairs expenditure across programmes, $2019 \ldots \ldots \ldots .6$

Figure 2.2 Community development expenditure across programmes, 2019 ............................ 6

Figure 2.3 Eight broad focus areas of DRCD expenditure, 2019.................................................. 7

Figure 3.1 Circular overview of community development policy impact evaluation................... 16

Figure 3.2 Sample outcome and impact metrics at small-area level relevant for (i) Rural development, (ii) Community development, (iii) Rural and community development. 


\section{ABBREVIATIONS}

\begin{tabular}{|c|c|}
\hline ADP & Addressing De-population \\
\hline CBA & Cost Benefit Analysis \\
\hline CDN & Community Development - National \\
\hline CDR & Community Development - Rural \\
\hline $\mathrm{Cl}$ & Capital infrastructure \\
\hline CSO & Central Statistics Office \\
\hline CSP & Community Services Programme \\
\hline CVM & Contingent Valuation Method \\
\hline DEASP & Department of Employment Affairs and Social Protection \\
\hline DiD & Difference-in-Differences \\
\hline DOJE & Department of Justice \\
\hline DPER & Department of Public Expenditure and Reform \\
\hline DRCD & Department of Rural and Community Development \\
\hline El & Enterprise Ireland \\
\hline $1 / 0$ & Input-Output \\
\hline IV & Instrumental Variables \\
\hline $\mathrm{JC}$ & Job Creation \\
\hline JLD & Jobseekers Longitudinal Database \\
\hline LAG & Local Action Groups \\
\hline LEAP & Learning, Evaluation and Planning \\
\hline MEP & Manufacturing Extension Partnership \\
\hline NDP & National Development Plan \\
\hline $\mathrm{PA} / \mathrm{T}$ & Public Amenities/Tourism \\
\hline PSM & Propensity Score Matching \\
\hline RD & Rural Development \\
\hline RDD & Regression Discontinuity Design \\
\hline RDI & Rural Development Index \\
\hline RDP & Rural Development Programme \\
\hline RRDF & Rural Regeneration and Development Fund \\
\hline $\mathrm{RV}$ & Rural Vitality \\
\hline SE & Support to Social Enterprises and SMEs \\
\hline SIA & Social Impact Assessment \\
\hline SICAP & Social Inclusion and Activation Programme \\
\hline TCM & Travel Cost Method \\
\hline WTA & Willing-to-Accept \\
\hline WTP & Willing-to-Pay \\
\hline
\end{tabular}




\section{EXECUTIVE SUMMARY}

The Department of Rural and Community Development (DRCD) was established in July 2017. Its mission is to 'promote rural and community development and to support vibrant, inclusive and sustainable communities throughout Ireland'. DRCD's Statement of Strategy 2021-2023 commits to building capacity to evaluate its work and impact to inform ongoing development of policies and programmes. As such, in September 2019 DRCD and the Economic and Social Research Institute (ESRI) entered into a joint Research Programme to help inform the Department's rural and community development policy. This report is the first output published under the Research Programme. Its aim is to identify international approaches to the evaluation of rural and community development activities. In turn, this will help to improve public knowledge of measurement and evaluation of projects with a rural and community development emphasis and help inform policymaking decisions of the Department.

All DRCD programmes and expenditure are targeted at rural and community development. However, DRCD programmes and expenditure are categorised into different areas of activity in this report to provide focus for the analysis of evaluation approaches internationally. Six main areas of activity were identified to review and examine the associated international approaches to evaluation. The majority of DRCD expenditure is targeted towards programmes with community and/or rural related objectives. For example, four programmes, focusing on either rural or community development, account for approximately 50 per cent of all DRCD expenditure in 2019. Therefore, most emphasis is placed on assessing international approaches in these areas. Many department programmes also involve capital spending. As such, a greater emphasis is also placed on approaches to evaluation in this area compared to other areas examined in this report i.e. enterprise supports, employment supports, and supporting/ developing amenities, which are outlined more briefly.

In general, there are specific challenges associated with measuring the causal impact of both community and rural development programmes. For other areas, such as capital expenditure, the framework is more easily defined with Cost Benefit Analysis (CBA) being the main method of assessment. Enterprise supports, employment and provision/development of amenities also generally have a clearer method for analysis. These overall findings and next steps are discussed below for each of the six main areas of department activities.

\section{Community development}

A review of methodological approaches in the international literature, and an assessment of the approach in an Irish context show that measuring key areas of 
DRCD activity such as community development is highly complex. Counterfactual analysis of community level outcomes is extremely difficult to implement. This allows for a comparison with the outcome an individual, business, or local area would have experienced had it been not exposed to the intervention. It can be difficult to attribute outcomes to particular programmes as many factors can simultaneously affect the outcomes of interest and attempting to disentangle and isolate the impacts of any particular policy intervention can be impossible in practice. However, other forms of effective monitoring are possible and recommended. It is suggested that a framework such as the Logic Model should be used in conjunction with a combination of quantitative and qualitative tools where possible. A Logic Model involves defining programme objectives, inputs, processes and outcome variables. Non-programme specific indicators may also be used to monitor changes in community development more broadly e.g. measures of income, poverty, educational attainment etc.

Current approaches to the evaluation of community development programmes in Ireland are found to be broadly in line with international best practice. It has been established that there exists a rich quantitative and qualitative data framework that will enable effective monitoring and impact measurement through a range of tools including the Logic Model framework, distance travelled tools and thematic qualitative reports (for example, see Whelan et al., 2019). ${ }^{1}$

\section{Rural development}

The methodologies and difficulties encountered for community development are also relevant to rural development. However, international literature shows that empirical methodologies may be more readily applied as there is some evidence of successful implementation of counterfactual evaluation in other countries (for example, see Michalek et al., 2020 and Gertler et al., 2016). Rural development is focused on improving the welfare of rural communities, but also encompasses aspects such as the improved utilisation of amenities within rural areas and the development of the rural economy. Therefore, interventions within the rural development space tend to be associated with more readily defined outcomes and, consequently, are more suitable for more formal evaluation approaches. From a methodological perspective, the following econometric approaches are suggested as appropriate for the evaluation of rural development programmes: (i) matching techniques, such as propensity score matching (PSM); (ii) Regression Discontinuity

Distance travelled tools can perform different functions. However, the main reason for measuring soft outcomes and distance travelled is to capture the benefits resulting from programme activities that would otherwise be missed if only hard outcomes are recorded (DWP, 2003; Learning and Work Institute, 2016). Thematic analysis is a qualitative research method that can be widely used across a range of research questions. It is a method to identify, analyse, organise, describe, and report themes found within a dataset (Braun and Clarke, 2006). Thematic analysis can be described as a translator for those speaking the languages of qualitative and quantitative analysis (Boyatzis, 1998). It enables researchers who use different research methods to communicate with each other. 
Design (RDD); (iii) Difference-in-Differences (DiD); and (iv) Instrumental Variables (IV), once the necessary data infrastructure is in place.

In terms of rural development metrics, effective monitoring techniques are also a relevant tool for measuring impacts in this area. Ideally the adoption of a framework that focuses on metrics specific to the objectives of the programme is most appropriate. Some metrics have been developed specifically for rural development analysis. For example, a Rural Development Index (RDI) based on socio-economic, environmental, infrastructural and administrative indicators has been used to measure overall rural development and quality of life in regions of EU countries.

Publicly available evaluations of rural development programmes are limited in Ireland. However, the data infrastructure and modelling tools appear promising. For example, a BIO-ECONOMY input-output model has been used for counterfactual impacts of large-scale rural investment programmes such as the Rural Development Programme (RDP) 2014-2020 for Ireland. Furthermore, the data infrastructure developed under the monitoring requirements of $\mathrm{EU}$ funded programmes, such as the LEADER programme, are likely to be an important data source for any formal attempts to measure the counterfactual impact of rural development interventions in Ireland. In addition, developments in official statistics at a national level such as the CSO's six-way urban/rural area categorisation of Ireland in 2019 could potentially be used to facilitate analysis of metrics at more distinct geographical levels.

\section{Capital infrastructure projects}

The evaluation methods related to capital infrastructure projects are long-standing and well developed. Under the Public Spending Code, proposals for capital spending must be presented along with an array of supporting information including ex-ante financial and economic evaluations of project proposals and suggestions for how ex-post evaluation will also be undertaken. The extent of the financial and economic analysis varies by the scale of the project, but Cost Benefit Analysis (CBA) is the main approach used for the evaluation of large-scale capital projects, both in Ireland and internationally. CBA requires the specification of a number of critical parameters including expected costs, benefits and the discount rate. However, methodological challenges exist for CBA, when applied ex-ante, mainly related to the accurate forecasting of costs and/or timelines, measuring benefits (including those that are non-monetary), the use of an appropriate discount rate and systematic optimism bias. In Ireland, weaknesses have been identified in terms of the appraisal, implementation and governance approaches applied to large-scale capital projects such as Metro North and the National Children's Hospital. In addition, the performance of capital projects can be 
evaluated further by examining costs and benefits outlined in project proposals with those realised after project completion. However, it can be difficult to establish whether the benefits are directly attributable to the project itself.

\section{Enterprise supports}

Evaluation of enterprise supports focuses on outcome variables related to firmlevel performance such as employment, turnover and profitability. In order to determine the impacts of supports evaluators will, in general, attempt to identify a control group of non-supported firms against which to benchmark the performance of supported enterprises. Evaluations may also focus on measuring the differential impacts of different forms of grant assistance on the performance of assisted firms; for example, the relative impact of marketing, capital, R\&D and employment grants on assisted firm performance (for example, see McGuinness and Hart, 2004).

Examining Ireland relative to other countries, there is a lack of counterfactual evaluation in the area of enterprise supports. This is somewhat surprising given the importance of enterprise within the Irish economic policy framework. This may be due, in part, to the lack of administrative or survey data that would facilitate such analysis. Of the studies that do exist in terms of SME supports, the research most consistent with international best practice was an analysis of small firm development and grant assistance in both Northern Ireland and the Republic of Ireland by Roper and Hewitt-Dundas (2001). International best practice in evaluating enterprise supports is clearly laid out in well cited publications by Storey $(1998 ; 2000 ; 2003)$ in which he identifies six key stages in evaluating the impact of supports to small businesses. These are also discussed in an Irish evaluation context in Lenihan et al. (2005). Of the six stages, the first three stages relate to effective monitoring, with the final three stages focusing on evaluation.

\section{Employment supports}

There are many studies published in Ireland using international approaches to measure the impact of employment supports. Evaluation approaches within these studies overall appear to meet international best practice standards. These approaches typically involve the use of 'treatment' and 'control' groups to evaluate impacts of employment supports i.e. the employment rate of supported jobseekers with a comparison group not in receipt of supports. However, it is important to note that many employment supports within the realm of community development target individuals facing more substantial barriers to employment (such as homelessness, physical or mental health problems, addiction issues, language difficulties, etc.). Such supports are more difficult to formally evaluate due to the problems of finding an appropriate control group. Mixed method (qualitative and quantitative) approaches are necessary to examine the impacts of 
such supports more fully (for example, see Whelan et al., 2020). Furthermore, the assessment of soft outcomes such as those measured through distance travelled tools can provide additional insights. ${ }^{2}$

\section{Amenities}

The evaluation of amenity projects varies considerably depending on the goals of the project, the data available and the budget available for evaluation. For example, amenity projects might include the development of local parks, woodlands, libraries and leisure facilities such as sports centres and swimming pools. The evaluation of amenities primarily focuses on the benefits to immediate users and this will generally, but not always, require some primary data collection.

There is a limited amount of literature evaluating the impact of amenities in Ireland but that which exists appears consistent with international best practice. There are two main approaches to valuing amenities. First, stated preference methods such as the Contingent Valuation Method (CVM) involve asking respondents about their willingness to pay (WTP) for amenities. Second, revealed preferences methods such as the Travel Cost Method (TCM) rely on data from real markets in order to draw conclusions on the value of non-market goods. For example, the TCM has been used to measure the impact of Greenways in Ireland which is an area of activity supported through DRCD programmes.

\section{Conclusions}

A number of approaches used to evaluate DRCD programme activity are identified in this report. While the approaches used in some areas (e.g. capital infrastructure projects, employment supports) are relatively clear, the counterfactual approaches used in other areas such as rural and community development tend to be more complex. However, monitoring and evaluation of DRCD programmes can be further enhanced through mixed methods approaches (including quantitative and qualitative techniques), combined with improvements in the type and consistency of data collected. This would further expand the opportunities to evaluate robust counterfactual impacts more formally particularly in terms of rural development projects. Non-programme specific data can be used to supplement this approach as a means to further monitoring impacts. The next stage in the research will involve the identification and analysis of appropriate key indicators for monitoring of rural and community development. 



\section{CHAPTER 1}

\section{Introduction}

\section{$1.1 \quad$ Introduction}

The Department of Rural and Community Development (DRCD) was established in July 2017. Its mission is to 'promote rural and community development and to support vibrant, inclusive and sustainable communities throughout Ireland'. DRCD programmes are diverse covering rural development, community development, social inclusion, capital infrastructure, employment schemes, depopulation initiatives, and the provision of amenities.

DRCD's Statement of Strategy 2021-2023 commits to building capacity to evaluate its work and impact to inform ongoing development of policies and programmes. To assist with this, in September 2019 DRCD and the Economic and Social Research Institute (ESRI) entered into a joint Research Programme which will initially run to the end of 2021. Under this Research Programme the ESRI will undertake research and analysis to:

- $\quad$ Support the monitoring and development of rural and community policy;

- Help develop a framework for monitoring and evaluation of rural and community development programmes;

- $\quad$ Produce bespoke outputs which help to inform Department policy areas and contribute to the analysis of specific programmes and projects funded by the Department.

This report, Review of International Approaches to Evaluating Rural and Community Development Investment and Supports, is the first output published under the Research Programme.

\subsection{Background context}

It is important to emphasise the distinction between monitoring and evaluation practices. Monitoring refers to the continuing or routine collection and use of data concerning an intervention for internal management and accountability reporting; whereas policy evaluation refers to the systematic assessment of the design, implementation and outcomes of a government's policy (HM Treasury, 2020). The main aims include to understand how a government intervention is being or has been implemented and what effects it has had, for which individuals and why. It also encompasses the identification of what can be improved and how, in addition to estimating overall impacts and cost-effectiveness. 
The OECD has identified six key criteria underpinning any evaluation including: relevance; coherence; effectiveness; efficiency; impact; and sustainability of the intervention (OECD, 1991; 2019). In Ireland, the original five OECD Development Assistance Committee (DAC) criteria above (excluding coherence) underpin the Public Spending Code. The Department of Public Expenditure and Reform (DPER) published the updated Public Spending Code: A Guide to Evaluating, Planning and Managing Public Investment in 2019. The Public Spending Code (PSC), published in 2013 , is the set of roles, procedures, and guidance to ensure Value for Money in public expenditure across the Irish Public Service. The Code applies to all organisations that spend public money. ${ }^{3}$

Two primary reasons to evaluate are learning and accountability (HM Treasury, 2020 , p.5). In terms of learning, evaluations can provide the evidence with which to manage risk and uncertainty, and further assist in good policy decision-making. Evaluation can provide evidence to inform decisions on whether to continue a policy, how to improve it, how to minimise risk, or whether to discontinue and invest elsewhere. In terms of accountability, Government makes decisions on behalf of individuals and spends tax collected from individuals and businesses. Therefore, government has an obligation to maximise public value and outcomes produced for taxpayers' money and government activity. Evaluation has a crucial role to play in this.

Stern (2015) argues that policymakers' purpose of evaluation has shifted from a largely accountability-based purpose to one that additionally concentrates on learning. Particularly, there is a focussed emphasis on understanding why and how programmes succeed or fail - over and above whether they succeed or fail - with the intention of improving current programmes and/or replicating them with confidence into the future.

\subsection{Objective of this report}

The aim of this report is to identify international approaches in monitoring and evaluation of rural and community development investment and supports. More specifically, this report concentrates on impact evaluation techniques and identifies specific methodologies (particularly counterfactual methods) which can potentially be used for assessing the impact of the types of programmes operated by DRCD. This will help improve public knowledge of measurement and evaluation of projects with a rural and community development emphasis and help inform policymaking decisions of the Department. It is important to note that further research will be completed under the Research Programme. This will build upon the analysis undertaken in this report to help form an overall framework of analysis 
which will support monitoring and evaluation of rural and community development programmes and policy.

\section{$1.4 \quad$ Methodology}

This report was undertaken using an analysis of DRCD programme expenditure and projects, desk-based research, previous ESRI programme evaluation research as well as consultation with DRCD. A general overview of DRCD activities is first outlined to identify the key areas of focus for the international review. This is followed by the international review of approaches in the measurement and evaluation of programmes which have a strong emphasis on rural and community development. A wide range of methodological approaches (quantitative, qualitative and mixed methods) employed internationally are considered. Irish evaluation approaches are subsequently benchmarked against identified international best practice.

An important subject related to public funding in general, and also to rural and community development, is the extent to which the funding actually supports the achievement of the policy objective. Although there is a substantial body of literature on the policy-implementation gap ${ }^{4}$ and on discrete aspects of implementation support, such as policy design or performance monitoring, there is relatively little international evidence on the use, or effectiveness, of coherent and comprehensive policy support programmes (Hudson et al., 2019).

There is a recent body of literature attempting to answer such questions and provide empirical estimates of the impact of rural and community development interventions (see for example, Michalek et al., 2020; Bakucs et al., 2019, Castaño et al., 2019). This literature highlights the substantial challenges that exist for academic researchers and policy evaluators alike, due to the highly complex and cross-sectoral nature of rural and urban communities and the multiplicity of outcomes associated with supports.

The selection of methodologies that can be applied to evaluate the impact of rural and community development interventions is wide ranging. Experimental approaches allow for robust comparisons through the random assignment of programme participants. However, the main barriers to the use of experimental approaches are due to the nature of community and rural development project implementation combined with ethical and representativeness issues. Therefore, evaluation methodologies predominately include quantitative, qualitative, and mixed methods (combination of quantitative and qualitative) approaches. 
Firstly, the main challenge across different evaluation methods is the appropriate identification of a counterfactual. This is the outcome an individual, business, or local area would have experienced had it been not exposed to the intervention. Other key decision factors associated with the choice of methodological approaches includes programme objectives, data availability, data types, budget, time constraints and the analytical skills and knowledge levels of the evaluators. It is important to be aware that the evaluation results can be sensitive to the overall context, assumptions and methods used. In summary, evaluations of the impact of rural and community development programmes will differ depending on many factors and often require some combination of appropriate methodologies, both quantitative and qualitative.

Measurement and evaluation of rural and community development programmes is important in order to provide evidence on whether specific programmes achieved their policy objectives. Furthermore, measurement and/or evaluation can also inform any re-design of a programme in order to increase its efficiency and effectiveness and/or continued relevance. Ultimately, robust evaluations should point towards either the continuation, adjustment or discontinuation of programmes based on estimates of the overall social and/or economic benefits associated with any particular policy interventions. Measurement and evaluation, ideally, go beyond an assessment of what has happened; why something has occurred is considered and, if possible, how much has changed as a consequence (European Commission, 2017a). Evaluation also provides a key opportunity to engage stakeholders and the general public.

\subsection{Structure of this report}

The remainder of the report is structured as follows:

- Chapter 2 identifies the key focus areas for the review of international literature through an examination of DRCD programme expenditure;

- $\quad$ Chapter 3 outlines approaches in evaluation methods internationally in six main areas of DRCD programme activity;

- Chapter 4 summarises evaluation approaches in an Irish policy context; and,

- $\quad$ Chapter 5 presents the conclusions of this report. 


\section{Overview and context}

\subsection{Introduction}

All DRCD programmes and expenditure are targeted at rural and community development. However, in this section DRCD programmes and expenditure are categorised into different areas of activity to provide focus for the analysis of evaluation approaches internationally. A number of documents provided to the ESRI were reviewed as part of this analysis. ${ }^{5}$ Data files provided by DRCD relating to the work of the Department were analysed. ${ }^{6}$ Consultation with DRCD also allowed for a more detailed classification of DRCD funding.

\subsection{Analysis of DRCD expenditure}

In 2019 DRCD gross expenditure was $€ 291$ million, of which $€ 153$ million was current expenditure and $€ 138$ million capital expenditure (DRCD). ${ }^{7}$ Rural development programme expenditure was mostly capital expenditure while community development programme expenditure was mainly current expenditure. The key components of capital expenditure dedicated to rural development in 2019 were LEADER (37 per cent) and the Rural Regeneration and Development Fund (25 per cent). The key components of current expenditure were the National Rural Development Schemes (59 per cent) and the Western Development Commission (22 per cent). brochure outlining its programmes/schemes in 2018, internal survey review documents, website material relating to the various programmes/schemes, and Pobal's website material relating to programmes/schemes e.g. SICAP, SSNO, SAS, PEACE IV, LEADER, Dormant Accounts, CSP.

6 These data files included an Excel file of RRDF projects by sub-categorisation, charts taken from a review of CSP, and an Excel file of LEADER projects by sub-categorisation.

7 Personal email communication from DRCD, 7 April 2020. 
FIGURE 2.1 RURAL DEVELOPMENT AND REGIONAL AFFAIRS EXPENDITURE ACROSS PROGRAMMES, 2019
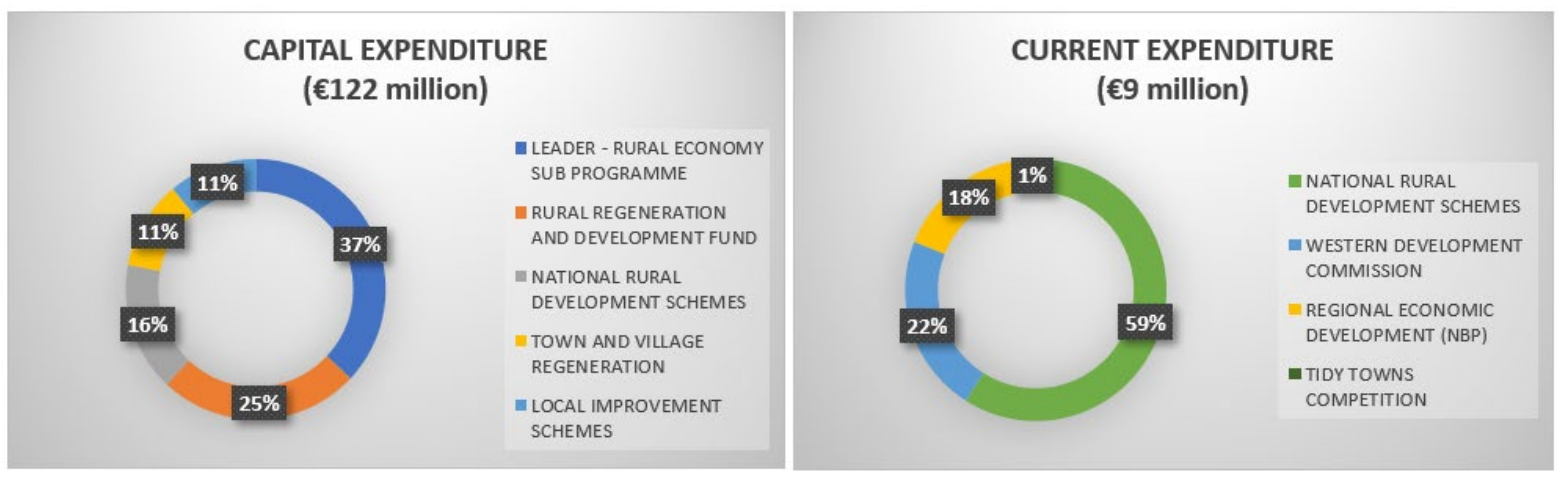

Source: $\quad$ Personal email communication from DRCD, 7 April 2020.

Notes: $\quad$ The data used are the actual expenditure out-turns for 2019 provided by DRCD where administration costs are excluded. The 'National Rural Development Schemes' category includes: Outdoor Recreation Infrastructure Scheme; the Walks Scheme; Coillte Trails; CLÁR; Tidy Towns Supports.

The vast majority of community development funding is in the area of current spending. The key components of current expenditure dedicated to community development in 2019 were the Community Services Programme (CSP) (36 per cent) and Social Inclusion and Activation Programme (SICAP) (34 per cent). The key components of capital expenditure (although a small proportion of overall community development expenditure) were the Library Development and Archive Service (40 per cent) and the Community Enhancement Programme (26 per cent). ${ }^{8}$

\section{FIGURE 2.2 COMMUNITY DEVELOPMENT EXPENDITURE ACROSS PROGRAMMES, 2019}

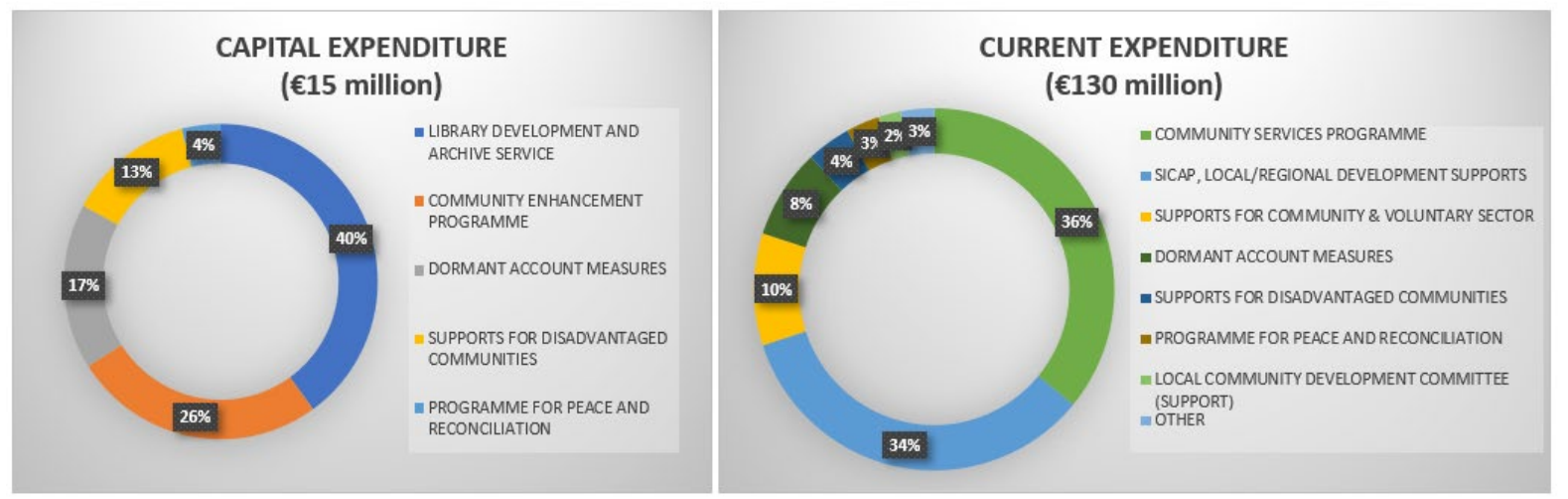

Source: $\quad$ Personal email communication from DRCD, 7 April 2020.

Notes: $\quad$ The data used are the actual expenditure out-turns for 2019 provided by DRCD where administration costs are excluded. The 'Other' category includes: Irish Water Safety; Library Development and Archive Service; Public Participation Networks; Social Inclusion Units; Dog Control.

The overview of DRCD funding allocations is presented in a simplistic way, although the framework is highly complex and multi-layered. Four programmes accounted for approximately 60 per cent of all DRCD expenditure in 2019. That is, (i) the Rural

8 The kinds of activities covered by these schemes are described in Chapter 3. 
Regeneration and Development Fund (RRDF); (ii) the CSP; (iii) SICAP; and (iv) the LEADER Programme. However, based on Table 2.1, eight broad focus areas of expenditure have been identified in Figure 2.3.

\section{FIGURE 2.3 EIGHT BROAD FOCUS AREAS OF DRCD EXPENDITURE, 2019}
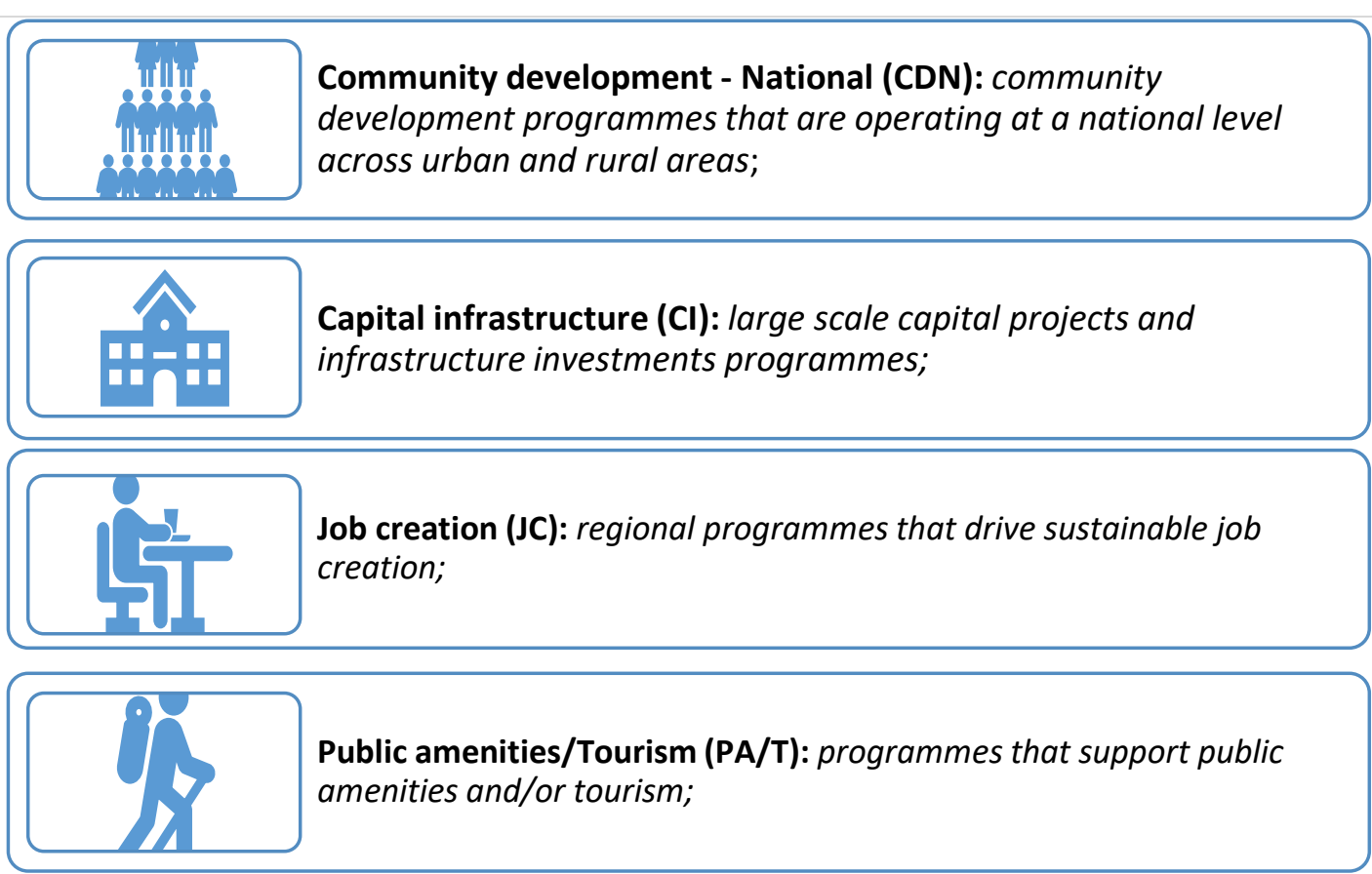

$\begin{aligned} & \text { Addressing de-population (ADP): programmes that aim to address } \\ & \text { depopulation of rural communities and support improvements to } \\ & \text { enhance their attractiveness for families who want to live and work } \\ & \text { there; }\end{aligned}$
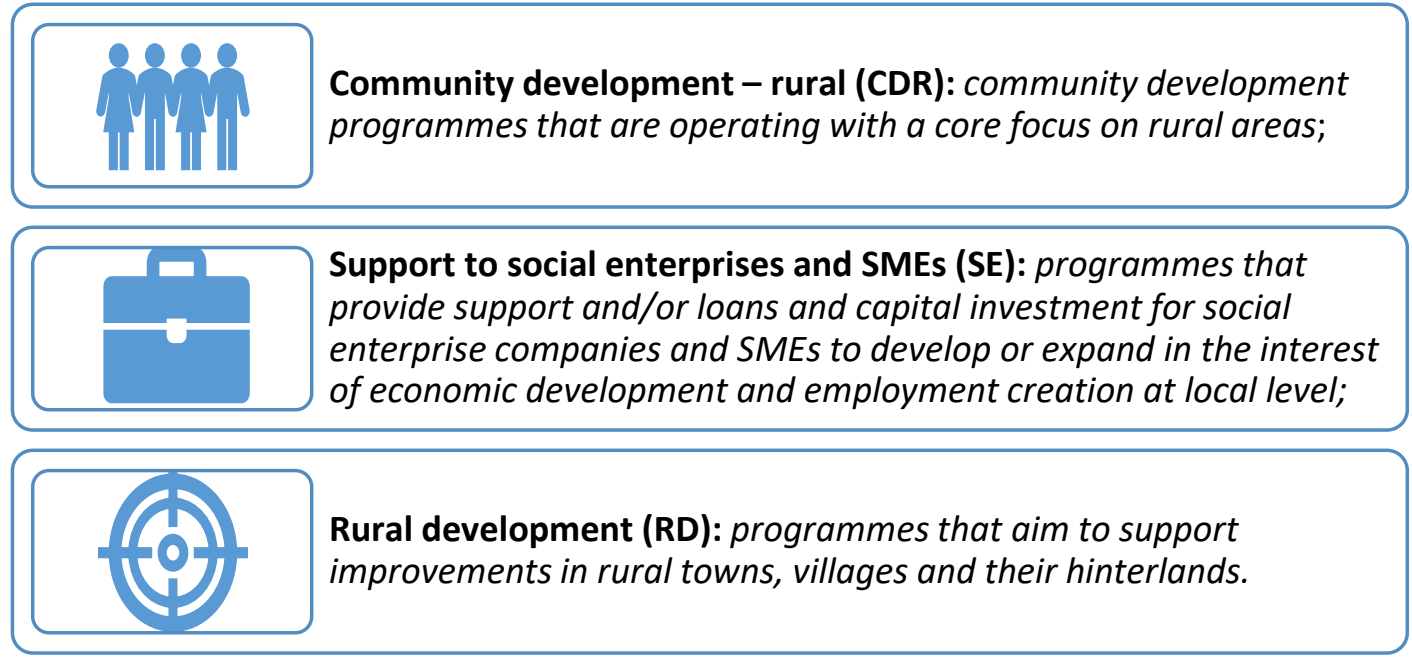

Source: $\quad$ Authors' own classification using information provided by DRCD.

It is important to outline that rural and community development have many similarities in that they seek to improve the well-being of individuals in a particular geographical area. Community development is defined as a developmental activity comprised of both a task and a process. The task is social change to achieve 
equality, social justice and human rights, and the process is the application of principles of participation, empowerment and collective decision-making in a structured and coordinated way (DRCD, 2019). Rural development can be seen as a subset of community development. Rural development is the process of improving the lives of people living and working in rural areas to ensure the success of vibrant rural communities across Ireland (DRCD, 2018).

Table 2.1 provides an overview of the total estimated DRCD funding allocations in 2019 by areas of activity that are associated with broad common goals and objectives. Where a significant proportion of funding from a programme (for each of the largest 20 programmes) has been allocated to a key focus area it is marked with an ' $X$ '. The key focus areas are ranked (across columns) from left to right in terms of the number of programmes that allocate a significant proportion of funding to activities in this broad area. The programmes are also ranked (by rows) from one to 20 in terms of their overall share of the total DRCD budget. Furthermore, we have identified the one broad common goal where the most significant amount of funding has been allocated (marked with a shaded pentagon sign) for each of these programmes. This aids the determination of the focus areas in which evaluation and monitoring activities should be most heavily concentrated. 
TABLE 2.1 OVERVIEW OF DRCD PROGRAMME EXPENDITURE IN 2019 ACROSS EIGHT BROAD AREAS INCLUDING: COMMUNITY DEVELOPMENT - NATIONAL (CDN); CAPITAL INFRASTRUCTURE (CI); JOB CREATION (JC); PUBLIC AMENITIES/TOURISM (PA/T); ADDRESSING DE-POPULATION (ADP); COMMUNITY DEVELOPMENT - RURAL (CDR); SUPPORT TO SOCIAL ENTERPRISES AND SMES (SE); RURAL DEVELOPMENT (RD)

AN ' $X$ ' INDICATES WHERE A SIGNIFICANT PROPORTION OF FUNDING FROM A PROGRAMME IS ALLOCATED TO A KEY FOCUS AREA I.E. COMMUNITY DEVELOPMENT - NATIONAL (CDN); THE SYMBOL $\square$ IDENTIFIES THE ESTIMATED KEY FOCUS AREA WITH THE HIGHEST PROPORTION OF EXPENDITURE FOR EACH PROGRAMME

\begin{tabular}{|c|c|c|c|c|c|c|c|c|c|c|c|c|c|c|}
\hline \multirow[b]{2}{*}{$\begin{array}{c}\text { RANK } \\
\text { (TOTAL } \\
\text { SPEND) } \\
\end{array}$} & \multirow[b]{2}{*}{ SECT. } & \multirow[b]{2}{*}{ PROGRAMME NAME } & \multirow{2}{*}{ 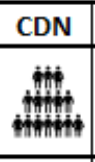 } & \multirow{2}{*}{\begin{tabular}{c|}
$\mathrm{Cl}$ \\
$\hat{\mathrm{H}}$
\end{tabular}} & \multirow{2}{*}{$\begin{array}{l}\text { JC } \\
\text { 돈휴 }\end{array}$} & \multirow{2}{*}{$\begin{array}{l}\mathrm{PA} / \mathrm{T} \\
\ddot{\gamma}\end{array}$} & \multirow{2}{*}{ ADP } & \multirow{2}{*}{\begin{tabular}{|c|} 
CDR \\
misevi \\
\end{tabular}} & \multirow[t]{2}{*}{ SE } & \multirow{2}{*}{ (C) } & \multicolumn{3}{|c|}{2019 ACTUAL EXPENDITURE $(€, 000)$} & \multirow[b]{2}{*}{$\%$} \\
\hline & & & & & & & & & & & CURRENT & CAPITAL & TOTAL & \\
\hline 1 & RD & LEADER - RURAL ECONOMY SUB PROGRAMME & & $\otimes$ & $\mathrm{x}$ & $\mathrm{x}$ & $\mathrm{x}$ & $\mathrm{x}$ & $\mathrm{x}$ & $\mathrm{x}$ & & 45,188 & 45,188 & 16.4 \\
\hline 2 & CD & COMMUNITY SERVICES PROGRAMME & $\otimes$ & & $\mathrm{x}$ & & & & $x$ & & 43,855 & & 43,855 & 15.9 \\
\hline 3 & $\mathrm{CD}$ & SICAP, LOCAL/REGIONAL DEVELOPMENT SUPPORT & $\otimes$ & & & & & & & & 43,265 & & 43,265 & 15.7 \\
\hline 4 & RD & RURAL REGENERATION \& DEVELOPMENT FUND & & $\otimes$ & $\mathrm{x}$ & $\mathrm{x}$ & $\mathrm{x}$ & $\mathrm{x}$ & & $\mathrm{x}$ & & 31,285 & 31,285 & 11.3 \\
\hline 5 & RD & NATIONAL RURAL DEVELOPMENT SCHEMES & $\mathrm{x}$ & $\mathrm{x}$ & $\mathrm{x}$ & $\widehat{\otimes}$ & $\mathrm{x}$ & & & & 4,881 & 18,986 & 23,867 & 8.6 \\
\hline 6 & RD & LOCAL IMPROVEMENT SCHEMES & & $\otimes$ & & & & & & & & 13,629 & 13,629 & 4.9 \\
\hline 7 & $\mathrm{CD}$ & SUPPORTS FOR COMMUNITY \&VOLUNTARY SECTOA & $\otimes$ & & & & & & & & 13,242 & 1 & 13,243 & 4.8 \\
\hline 8 & RD & TOWN AND VILLAGE REGENERATION & & $\otimes$ & $\mathrm{x}$ & $\mathrm{x}$ & $\mathrm{x}$ & $\mathrm{x}$ & & & & 12,999 & 12,999 & 4.7 \\
\hline 9 & CD & DORMANT ACCOUNT MEASURES & $\widehat{\otimes}$ & & $\mathrm{x}$ & & & & $x$ & & 10,100 & 2,655 & 12,755 & 4.6 \\
\hline 10 & CD & PROGRAMME FOR PEACE \& RECONCILIATION & & & & $\mathrm{x}$ & & $\otimes$ & & & 7,695 & 650 & 8,345 & 3.0 \\
\hline 11 & CD & LIBRARY DEVELOPMENT \& ARCHIVE SERVICE & $\otimes$ & $\mathrm{x}$ & & $\mathrm{x}$ & & & & & 1,282 & 6,048 & 7,330 & 2.7 \\
\hline 12 & CD & SUPPORTS FOR DISADVANTAGED COMMUNITIES & $\underline{\otimes *}$ & $\mathrm{x}$ & & & & & & & 5,098 & 1,904 & 7,002 & 2.5 \\
\hline 13 & $\mathrm{CD}$ & COMMUNITY ENHANCEMENT PROGRAMME & $\otimes$ & $\mathrm{x}$ & & $\mathrm{x}$ & & & & & & 4,000 & 4,000 & 1.4 \\
\hline 14 & $\mathrm{RD}$ & REGIONAL ECONOMIC DEVELOPMENT & & $\mathrm{x}$ & $\mathrm{x}$ & & $\mathrm{x}$ & & & $\widehat{\otimes}$ & 1,692 & 380 & 2,072 & 0.8 \\
\hline 15 & RD & WESTERN DEVELOPMENT COMMISSION & & & $\mathrm{x}$ & & $\mathrm{x}$ & & $\mathrm{x}$ & $\otimes$ & 2,015 & & 2,015 & 0.7 \\
\hline 16 & CD & LOCAL COMMUNITY DEVELOPMENT COMMITTEE & $\otimes$ & & $\mathrm{x}$ & & & & & & 1,904 & & 1,904 & 0.7 \\
\hline 17 & CD & PUBLIC PARTICIPATION NETWORKS & $\otimes$ & & & & & & & & 1,750 & & 1,750 & 0.6 \\
\hline 18 & $\mathrm{CD}$ & IRISH WATER SAFETY & $\otimes$ & & & & & & & & 1,118 & & 1,118 & 0.4 \\
\hline 19 & CD & SOCIAL INCLUSION UNITS & $\otimes$ & & & & & & & & 546 & & 546 & 0.2 \\
\hline 20 & RD & TIDY TOWNS COMPETITION & $\otimes$ & & & $\mathrm{x}$ & & & & & 1 & & 1 & 0.0 \\
\hline & & TOTAL & 13 & 9 & 9 & 8 & 6 & 4 & 4 & 4 & 138,444 & 137,725 & 276,168 & 100.0 \\
\hline
\end{tabular}

Actual expenditure out-turns for 2019 were provided by DRCD with administration costs excluded. For the estimated shares across the broad categories RRDF programme project approvals were used (and not expenditure) from 2017 to 31 January 2020. Similarly, LEADER programme project approvals were used (and not expenditure) again from 2017 to 31 January 2020 . A breakdown of CSP funding was estimated using CSP organisations that received funding since 2014 by Benefacts sub-sector. Pobal data were used by DRCD to match on CSP organisations of Irish non-profits collected by Benefacts and only 80 per cent of organisations could be matched (Personal email communication from DRCD, 7 April 2020). The 'NATIONAL RURAL DEVELOPMENT SCHEMES' Category includes: Outdoor Recreation Infrastructure Scheme; The Walks Scheme; Coillte Trails; CLAR Programme; Tidy Towns Supports. The symbol '*' indicates that the funding for this programme was focussed predominately on the urban area of Dublin North-East Inner City. 
On consideration of DRCD documentation and the evaluation techniques which will be discussed further in Chapters 3 and 4 of this report, we grouped some of the classifications used in Figure 2.3. We broadly examine the literature following six relevant focus areas: (i) community development and (ii) rural development including the relevant DRCD categories of community development - national $(C D N)$, community development - rural (CDR), rural development (RD) and addressing de-population (ADP); (iii) capital infrastructure (Cl); (iv) enterprise supports to address support to social enterprises and SMEs (SE); (v) employment supports to analyse job creation (JC); and (vi) public amenities/tourism (PA/T).

\subsection{Summary}

A key finding based on our estimates of the total breakdown (across DRCD's largest four programmes $)^{9}$ is that DRCD expenditure is predominately focussed on community and rural development (approximately 50 per cent of total expenditure in 2019). A lower proportion of funding appears to be allocated to capital investment and the development and promotion of amenities/tourism with the lowest proportion allocated to supporting employment and enterprise.

Therefore, it is clear from our analysis that the majority of DRCD expenditure is targeted towards programmes with either rural and/or community related objectives. Consequently, we will place a considerable emphasis on assessing international best practice in these areas. Furthermore, as many community and rural schemes also involve significant amounts of capital spending, we will also place a higher emphasis on evaluation approaches in this area. Other areas relevant to DRCD activities (such as developing amenities, job creation, and employment supports) will be outlined more briefly. 


\section{Review of international approaches}

\subsection{Introduction}

This chapter of the report reviews international approaches in monitoring and evaluation of DRCD's key activities which were identified in Chapter 2 of this report. The areas considered below include: (i) community development, (ii) rural development, (iii) capital infrastructure projects, (iv) enterprise supports, (v) employment supports, and (vi) amenities.

\subsection{Community development}

Within the academic and policy literature, a number of theoretical frameworks exist that could potentially be used for measuring community development, and these are discussed in the following paragraphs. They include the Logic Model (Milstein and Chapel, 2011), Four Pillar Approach (Pritchard and Kazimirski, 2014), ABCD Framework (Barr and Hashagen, 2000), LEAP Model (Barr and Dailly, 2007) and the Theory of Change (Rogers, 2014). While it is not clear that any particular one of these conceptual frameworks should guide the measurement of community development, each of these theories generally involve a clear statement on programme objectives, which are linked explicitly to inputs, processes and outcome variables that the policy should be influencing. ${ }^{10}$ All of these frameworks face the distinct challenge of establishing a causal relationship between the programme intervention and changes in outcome (discussed further in Section 3.2.7).

\subsubsection{Logic Model}

A Logic Model is a tool used by funders, managers and evaluators of programmes to evaluate the effectiveness of a community development programme, providing a simple framework under which metrics related to community development can be captured (Milstein and Chapel, 2011). This model has proved to be a successful tool for programme planning as well as implementation and performance management in numerous fields, including primary care (Frechtling, 2007).

10 In addition, social impact assessment (SIA) is a broad process of managing the social issues of development (Esteves et al., 2012). It is described as participatory; supporting affected peoples, proponents and regulatory agencies; increasing understanding of change and capacities to respond to change; seeking to avoid and mitigate negative impacts and to enhance positive benefits across the life cycle of developments; and emphasises enhancing the lives of vulnerable and disadvantaged people. Esteves et al. (2012) analyse the strengths, weaknesses, opportunities and threats facing SIA. For more information, please see Social Impact Assessment Hub at https://socialimpactassessment.com/index.asp. 
While there are many ways in which Logic Models can be depicted, in the simplest form, four components of a programme are used: inputs (resources), activities, outputs and outcomes (Table 3.1). The Logic Model shows the logical relationships among the resources that are invested, the activities that take place, and the benefits or changes that result. The purpose of its construction is to attempt to assess the 'if-then' (causal) relationships between the elements of the programme.

\section{TABLE 3.1 PROGRAMME ACTION AND LOGIC MODEL EXAMPLE}

\begin{tabular}{|l|l|l|l}
\hline \multicolumn{1}{c|}{ Inputs } & \multicolumn{1}{c|}{ Activities } & \multicolumn{1}{c}{ Outputs } & \multicolumn{1}{c}{ Outcomes/Impacts } \\
\hline $\begin{array}{l}\text { What resources go } \\
\text { into a programme? }\end{array}$ & $\begin{array}{l}\text { What activities does the } \\
\text { programme undertake? }\end{array}$ & $\begin{array}{l}\text { What is produced } \\
\text { through those activities? }\end{array}$ & $\begin{array}{l}\text { What are the changes or } \\
\text { benefits that result from the } \\
\text { programme? }\end{array}$ \\
\hline
\end{tabular}

Source:

Milstein and Chapel, 2011.

\subsubsection{Four Pillar Approach}

Pritchard and Kazimirski (2014) have published a 'four pillar approach', in association with New Philanthropy Capital (NPC), providing practical guidance on developing an impact measurement framework. The four pillars can be summarised as: (i) mapping the Theory of Change; ${ }^{11}$ (ii) prioritising what is measured; (iii) choosing the level of evidence; and (iv) selecting the sources and tools. Furthermore, they propose that the outcomes assessed should be ones that are directly influenced (rather than indirectly supported); are important or material to the mission of the programme; are not too costly to measure; and will produce reliable data.

\subsubsection{ABCD Framework}

The ABCD Framework is a detailed approach for planning, evaluating and learning from community development interventions devised by the Scottish Community Development Centre (Barr and Hashagen, 2000). The method aims to ensure that there is clarity about: (i) the aims of community engagement activity; (ii) what activities will be undertaken; and (iii) how success will be measured.

The framework sets out ten dimensions of community development in a structure of 'a healthy community', 'a strengthened community', 'quality of community life dimensions' and 'community empowerment dimensions'.

This framework has been used as the basis for the Learning, Evaluation and Planning (LEAP) approach to identify three bases of evaluation (Barr and Dailly, 2007): (i) expressed (from the viewpoint of the participants); (ii) normative 
(relative to standards set down by authorised bodies and experts); and (iii) comparative (relative to conditions in other areas).

\subsubsection{LEAP Handbook}

The LEAP Handbook (Barr and Dailly, 2007) suggests a framework to identify outcome indicators, stressing that indicators need to be developed on a case-bycase basis to reflect the priorities of the stakeholders in an initiative, which relates to the following questions: (i) How much has changed? (Quantity); (ii) How beneficial has the change been? (Quality); (iii) Who has benefited and who has not? (Equity); (iv) What resources have been used? (Efficiency); and (v) How far have the planned outcomes been achieved? (Effectiveness).

The LEAP model advocates the development of meaningful indicators in collaboration with the stakeholders. This model suggests limiting the collection of data to answering the questions that are most relevant to understanding these issues (optimal ignorance), and not gathering data with more accuracy than is needed to understand the priority issues for evaluation (appropriate imprecision). They state that a useful indicator is measurable, precise or accurate, consistent and sensitive (changing proportionally in response to actual changes).

\subsubsection{Theory of Change}

Developing a Theory of Change (ToC) model normally involves considering the proposed inputs (what investment, regulation, actions will take place) and the causal chain that leads from these inputs through to the expected outputs and outcomes (HM Treasury, 2020). It reflects the causal mechanisms by which an intervention is expected to achieve its outcomes and this theory is based on the gathering and synthesis of evidence. It can be developed for any level of an intervention, for example, an event, a project, a programme, a policy, a strategy or an organisation (Rogers, 2014).

In order to understand how and if a policy intervention is working, it is necessary to understand how its activities are expected to lead to the desired results. This process requires understanding both: (i) the impact pathway showing the causal linkages from activities to outputs, to a sequence of outcomes, to impacts; and (b) the causal assumptions showing why and under what conditions the various links in the impact pathway are expected to work. A ToC aims to combine these elements and add to the impact pathway by describing the causal assumptions behind the links in the pathway, or what is necessary for the causal linkages to be realised (Mayne, 2015). Patton (2008) further clarifies this by specifying that consideration of such causal mechanisms transforms a Logic Model into a ToC. 
ToC can be used for strategic planning or programme/policy planning. During implementation, ToC can be used to identify which indicators must be monitored, and in impact evaluation to identify the data that need to be collected and how they should be analysed. It also provides a framework for reporting.

\subsubsection{Other conceptual approaches}

A less structured approach is suggested by Motherway (2006), who states that typical positive impacts of community development initiatives relate to more resources reaching excluded groups and communities; better facilities and services being provided; earlier, more effective interventions, especially in education; rising levels of participation and involvement; and, crucially, lower levels of measurable poverty in deprived communities. Emphasis is also placed on factors such as empowerment, increased levels of community spirit and mobilisation, and improved levels of community well-being generally. In general, there are limited quantitative elements in the evidence base and no systematic set of numerical indicators by which to measure impacts.

While it is not clear that any particular conceptual framework should guide the measurement of community development, it should be noted that each approach outlined generally incorporates a clear statement on programme objectives, which are then linked explicitly to subsequent inputs and identified key outcome variables that the policy should be influencing.

\subsubsection{Measuring counterfactual impacts}

Counterfactual analysis allows the outcomes of the intervention to be compared with the outcomes that would have been achieved in the absence of the intervention. International best practice for evaluating community development programmes were extensively assessed in Whelan et al. (2019). This study looked at the SICAP programme in Ireland and examined how programme impacts could be effectively measured. After evaluating the international literature, a principal conclusion of the study was that difficulties in untangling causal relationships made it virtually impossible to generate robust counterfactual estimates of programme impacts. The analysis pointed out that it was impossible to identify causal links between community development expenditure and general levels of community well-being, such as those included in 'Community Tool Box' developed by the University of Kansas Work Group for Community Health and Development (1994). ${ }^{12}$ 
Proposed metrics suggested in the 'Community Tool Box' attempt to measure community-level well-being using very broad aggregates that are not linked to any particular policy intervention (Milstein and Chapel, 2011). Examples include measures of income, poverty, deprivation, educational attainment, unemployment rates, workforce entry, social welfare payment discontinuation, community participation, membership in clubs and community associations, number of community activist and citizen advocacy groups and organisations, political participation (percentage of individuals voting), diversity of population, average price of a single family house, average rental rates, average commuting times, number of (current and new) local businesses, local revenue from taxes and fees, number of service firms, number of new commercial buildings being constructed, occupancy rates, etc.

Across the literature, we have found no evidence of any systematic attempts to practically measure a counterfactual estimate of community level outcomes. Our previous research has highlighted many reasons why this might be the case. Whelan et al. (2019) point out that many factors will simultaneously affect these outcomes, and attempting to disentangle and isolate the impacts of any particular policy intervention is extremely difficult. Whelan et al. (2019) propose the adoption of a monitoring framework that focuses on metrics specific to the objectives of the programme. However, even when programme specific metrics are established, causal relationships are extremely difficult to extract given the structure of funding to bodies implementing community development programmes such as SICAP and the CSP. For instance, in 2016, the average SICAP funding was found to account for an average of approximately 16 per cent of the total budgets to programme implementers (Darmody and Smyth, 2018).

Other barriers to measuring counterfactual impacts within a community development context include the difficulty in identifying control groups where no community development assistance took place, identifying appropriate common outcome metrics given the diverse objectives of community groups, and identifying the appropriate timeframe over which impacts should be measured. The principal barriers to identifying causal outcomes for community development expenditure are summarised in Figure 3.1. The key issue relates to the ability of researchers to demonstrate a causal link between a policy intervention and changes in broad measures of community well-being, shown by the break in the circular overview (Figure 3.1) between points (1) and (3). 


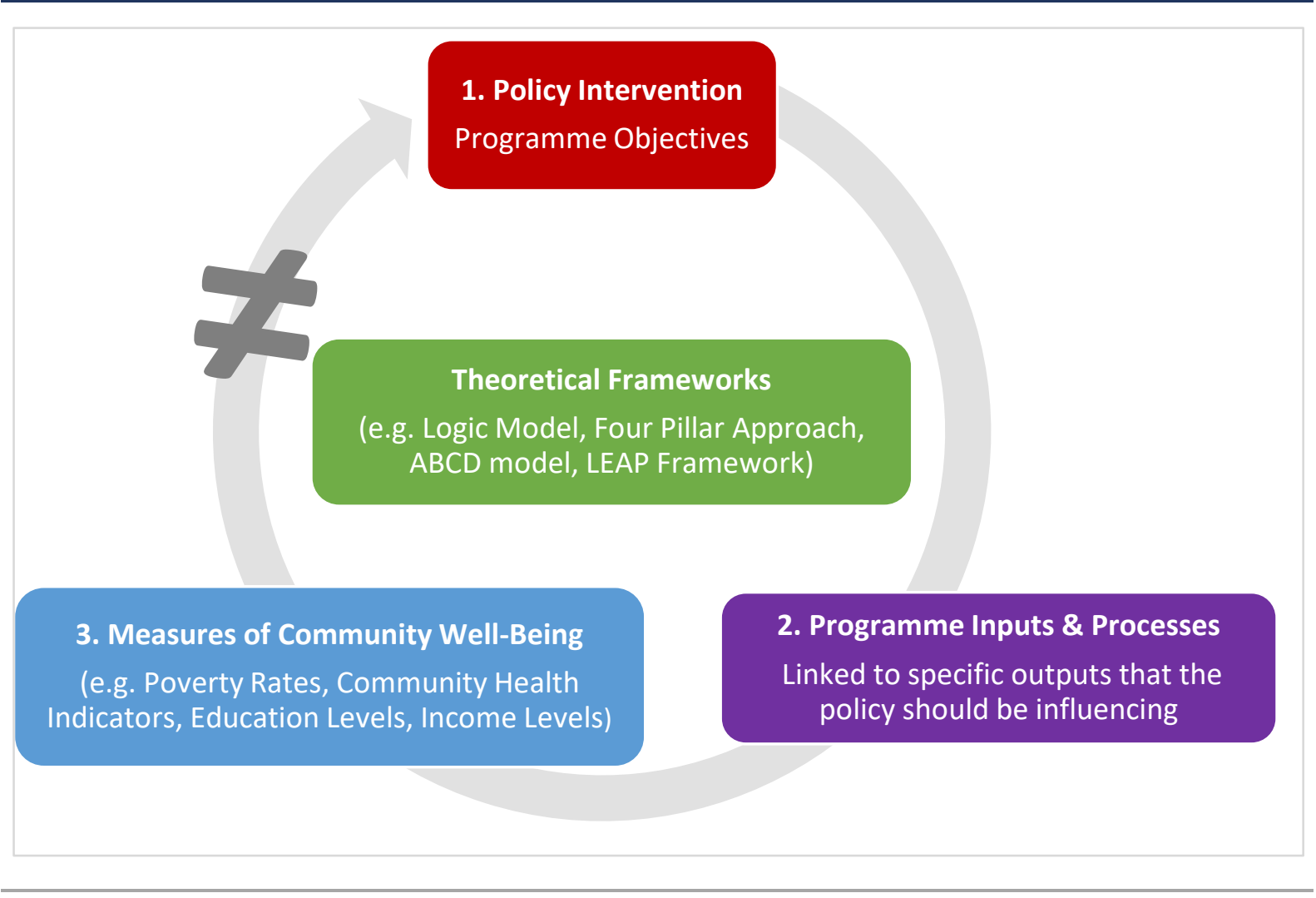

Source: Whelan et al., 2019.

The confounding factors contributing to the difficulties of trying to estimate the causal impact of policies targeting community well-being, identified in Whelan et al. (2019) are:

- Numerous national agencies simultaneously implement policies that will affect such broad outcomes making it difficult to isolate the impacts of one particular policy;

- Local organisations targeting specific communities often receive funding from multiple sources, making it impossible to measure the impact of a particular funding stream even in instances where the community level outcome measures are narrowly defined and identifiable;

- It may be more feasible to focus on more narrow outcomes for the purpose of evaluating the impact of funding to community level organisations. However, local community organisations tend to be highly heterogeneous in nature with differing objectives, making it extremely difficult to identify a set of specific community level outcome measures relevant to the activities of all funded groups;

- It is extremely difficult to identify control groups at a community level who have not been subject to any policy interventions against which to measure the counterfactual impact of an intervention. 
Therefore, the expectation of measuring any causal influence of SICAP on broad community level outcomes, such as poverty rates or levels of educational attainment, was not felt to be practical in Whelan et al. (2019) due to the existence of various streams of funding targeting such outcomes and the overall complexity of the system.

Nevertheless, community development, similar to all government-funded activities, requires monitoring and measurement. Whelan et al. (2019) suggest that the most appropriate framework for assessing the impact of community development expenditure involves approaches such as a Logic Model framework linked specifically to programme objectives that would allow for the monitoring of key outcome variables over time. A number of other similar monitoring frameworks could be considered including the Four Pillar Approach, the $A B C D$ Model and the LEAP framework. Further recommendations include the adoption of a community level distance travelled tool, and the commissioning of thematic qualitative studies that periodically collect evidence of themes related to programme goals.

\subsection{Rural development}

Rural and regional economic and social development is a core part of improving the quality of life in rural areas, small towns and villages. DRCD outlines that a dual process of developing rural areas requires:

- Working across government to advance the economic and social growth of rural areas in order to enhance the quality of life for people who live in rural Ireland; and,

- $\quad$ Contributing to enhanced regional progress, with a view to strengthening the potential of all regions to contribute to economic recovery.

The evaluation of rural development initiatives faces many of the same barriers as the evaluation of community development. In particular, rural development programmes will usually attempt to affect several outcome variables simultaneously, with such outcomes typically impacted by multiple other policy interventions. Consequently, this makes it very difficult to isolate the impact of any particular expenditure stream. However, many of the monitoring and qualitative methodologies recommended for community development (e.g. Logic Model framework, distance travelled tools and the commissioning of thematic qualitative studies) will also be relevant to projects funded by the Department under rural development. Some additional specific tools are also likely to be of use as discussed below. 
Figure 3.2 outlines a sample of potential outcome and impact metrics that are relevant to monitoring and evaluation in the areas of: (i) rural development, (ii) community development, and (iii) rural and community development. This illustration demonstrates the metrics where there is an overlapping focus and where separate metrics and analysis are required.

\section{FIGURE 3.2 SAMPLE OUTCOME AND IMPACT METRICS AT SMALL-AREA LEVEL RELEVANT FOR (I) RURAL DEVELOPMENT, (II) COMMUNITY DEVELOPMENT, (III) RURAL AND COMMUNITY DEVELOPMENT}

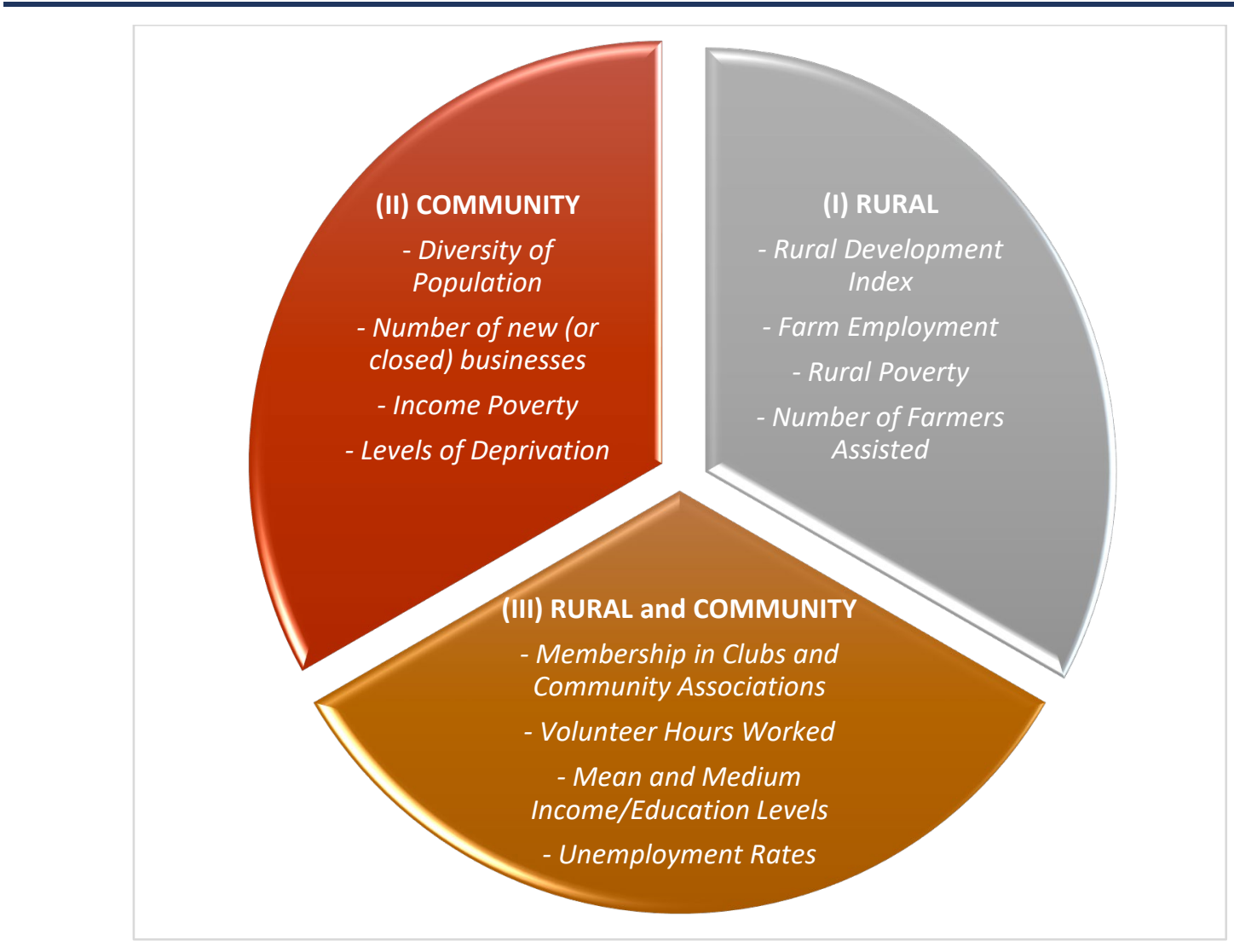

\subsubsection{Rural Development Index}

Michalek and Zarnekow (2012) and Abreu et al. (2019) propose the construction of a multi-dimensional (composite) index measuring the overall level of rural development and quality of life in individual rural regions of a given EU country. In the Rural Development Index (RDI) proposed by Michalek and Zarnekow (2012) the rural development domains are represented by detailed socio-economic, environmental, infrastructural and administrative indicators/variables at NUTS 4 level. ${ }^{13}$ Due to its comprehensiveness the RDI Index is suitable both to analysis of the overall level of development of rural areas and to an evaluation of the impacts 
(impact indicator) of rural development and structural programmes at regional levels (NUTS 2-5).

\subsubsection{Other rural development metrics}

In terms of additional rural development metrics, ideally the adoption of a monitoring framework that focuses on metrics specific to the objectives of the programme is most appropriate. However, the use of broad aggregates that are not linked to any particular policy intervention could be included as part of the monitoring and evaluation framework. Examples include the employment rate, shares of individuals working and living in rural areas, share of location neutral jobs, economically active population in rural areas, employment creation, farm employment, degree of rural poverty, rural GDP per capita, levels of (rural) investment, numbers of projects in rural areas, numbers of project beneficiaries in rural areas, broadband availability, quality of life and well-being in rural areas, local amenities, and educational attainment in rural areas.

\subsubsection{Measuring counterfactual impacts}

Counterfactual analysis has been recommended as a means of assessing the impacts of Rural Development Programmes (RDP) in Europe over recent years, although its application has been scarce to date (Castaño et al., 2019). However, the assessment of the impact of any rural development programme is often driven by data availability, the type of the rural development measure to be analysed, the geographical coverage and the econometric approach (Michalek et al., 2020).

Gertler et al. (2016), EENRD (2014), European Commission (2013), Loi and Rodrigues (2012), and Khandker et al. (2009), provide guidelines on counterfactual analysis to improve policy impact evaluation procedures. From a methodological perspective, they each consider the following econometric approaches as appropriate for the evaluation of rural development programmes: (i) matching techniques, such as propensity score matching (PSM); (ii) Regression Discontinuity Design (RDD); (iii) Difference-in-Differences (DiD); and (iv) Instrumental Variables (IV). These econometric techniques are discussed further in Appendix B to this report.

A number of essential components are required before counterfactual analysis to estimate the net impacts can take place. The measurement of any counterfactual requires the following key elements:

- Data on the relevant outcomes of programme beneficiaries over a given period of time. This is known as the 'treatment group'; 
- Data on the relevant outcomes of non-beneficiaries who, while qualifying for the programme did not benefit from it. This is known as the 'control group';

- If non-beneficiaries do not exist, data must be collected on the level of programme intensity for individual programme beneficiaries. This can allow for the application of more advanced counterfactual measurement approaches (for example, generalised propensity score matching);

- Data collected must be robust enough to eliminate any possible selection or other forms of evaluation biases (EENRD, 2014).

\subsubsection{Rural development evaluation studies}

In terms of specific rural development measures, the most frequent measures analysed within the literature relate to farm investment support (see for example, Bartova and Hurnakova, 2016; Kirchweger et al., 2015; Kirchweger and Kantelhardt, 2015; and Michalek et al., 2016). Only a small number of studies in the international literature focus on rural development impacts relating to regional well-being or the quality of life in rural areas. Recent relevant examples in the international literature include Bakucs at al. (2019); Mack et al. (2018); Michalek and Zarnekow (2012); and Michalek (2012b).

Research papers that have evaluated the effects of European rural development payments on quality of life are still exceptionally rare because of the complexity and variable uptake of these payments, the rural diversity of the European Union, and the often unclear targets of the measures (Midmore et al., 2008; Michalek, 2012; Mack et al., 2018). Other papers evaluating rural development payments focus on the impact on economic performance (Medonos et al., 2012; Hlavsa et al., 2017), structural change (Kirchweger et al., 2015) or employment (Petrick and Zier, 2011).

In order to analyse the impact of rural development programmes in Hungary, Bakucs et al. (2019) assess two indices of local well-being. First, a multidimensional, local-variable-based Regional Development Index that aims to encompass the overall level of regional development. Second, a simple, migrationbased index as a proxy for perceived quality of life. To estimate the impacts, econometric techniques were employed to evaluate the impact of the rural development programme subsidies. Their findings show that, regardless of how the amount of support was calculated, the measure of local well-being, or the methodology used, no significant impacts were found. In some cases the impact was even negative, therefore casting considerable doubt over the effectiveness of rural development policy in Hungary. 
Using counterfactual econometric methods, Mack et al. (2018) evaluate the effects of rural development payments on rural vitality (RV) in Romania. Hart et al. (2011) summarise RV as relating to the availability of a threshold level of economic opportunity, a minimum level of services and infrastructure, in addition to human capacity and operational social networks to sustain the long-term viability and attractiveness of rural areas as places to live, work and visit. Mack et al. (2018) use this concept to build an index of RV which includes information on attributes relating to population, economic activity and facilities. Their study shows that the design and uptake level of the rural development measures highly influenced the effects of the payments in Romania. The majority of payments focusing primarily on the competitiveness of the agricultural sector show either no effect or a negative effect on secondary targets such as improving quality of life of the rural population. However, they find that the more payments dedicated to non-agricultural activities, the higher the impact on RV.

In order to estimate impacts of the Rural Development Programme (RDP) on the performance of the food processing sector in Poland, Michalek et al. (2020) use a regional quasi-experimental estimation approach. The application of the regional approach in Michalek et al. (2020) allows for the estimation of the overall regional effects of the support provided. The data used include non-treated regions, allowing for the identification of a 'control' group and the use of a binary approach. Regions also differ in whether they received higher or lower levels of support i.e. the intensity of support. The authors exploit these differences by combining the use of generalised propensity score matching (across 15 covariates) and a doseresponse function (devised by Hirano and Imbens, 2004 and Bia and Mattei, 2008) to estimate the effects of various support intensity levels on the performance of the food processing sector in Poland. The impacts on structural change and employment in this sector are highlighted. The support was shown to cause many firms to exit, but at the same time it contributed to the creation of new firms and their overall increase. In terms of employment, the supports led to a reduction of labour in the food processing sector, likely due to the fact that the support induced the substitution of labour for capital/machinery. Furthermore, the generalised propensity score matching approach used for estimating the effects shows that the support effects varied with the funding intensity level, suggesting different policy efficiency depending on its size.

The Rural Development Programme (RDP) 2014-2020 outlines an extensive framework proposed for evaluating innovation in rural development programmes (European Commission, 2017b). They highlight that innovation is a cross-cutting theme of the RDP. The proposed framework may also have applicability for other rural development programmes and incorporates recent developments in agricultural research for development (AR4D), agricultural extension and research evaluation literature on the importance of identifying impact and outcome 
pathways when trying to evaluate interventions. Furthermore, Maye et al. (2020) provide an overview of applications of Theory of Change in rural policy evaluation focusing on an evaluation of the Badger Vaccine Deployment Project (BVDP) in England to reduce the incidence of bovine Tuberculosis (bTB) in cattle. They consider both the advantages and limitations to theory-based evaluation, and the contribution it can make to the evaluation of other rural development programmes. Maye et al. (2020) emphasise that although theory driven approaches to evaluation are not common within European evaluations of rural development initiatives, they are more frequently used to develop and evaluate rural policy in developing countries.

A range of methods which have been applied to develop rural development indicators have been reviewed by Michalek and Zarnekow (2012). Composite index approaches are recommended as most suitable to measure different aspects of quality of life in rural areas and the diversification of the rural economy. The generation of a counterfactual situation was solved by Computable General Equilibrium (CGE) modelling (Psaltopoulos et al., 2011), and PSM methodologies (Bakucs et al., 2019; Bartova and Hurnakova, 2016; Kirchweger et al., 2015; Kirchweger and Kantelhardt, 2015; Michalek, 2012a; 2012b; Michalek et al., 2014; 2016; 2018; Petrick and Zier, 2011). Other possible modelling approaches are discussed in Castaño et al. (2019) such as experimental approaches and simulation or structural models.

Experimental approaches allow for robust comparisons through the random assignment of programme participants. However, the main barriers to the use of experimental approaches are due to the nature of rural development project implementation combined with ethical and representativeness issues.

With relation to macro simulation or structural models, regional computable general equilibrium (CGE) models, mathematical programming (MP) and inputoutput (I/O) models have also been used (for instance, see Schroeder et al., 2015 and Monsalve et al., 2016), but the policy impact guidelines do not consider these approaches to fully address counterfactual analysis in ex-post settings (Gertler et al., 2016; European Commission, 2013; Loi and Rodrigues, 2012). Examples of recent macro-level econometric evaluation approaches within the literature include FGUVA (2016) and Grealis and O'Donoghue (2015) who employ I/O modelling approaches, and Laporta et al. (2016) who used a production functionbased regression approach.

Our initial assessment of the wider rural development literature is that it tends to rely on qualitative evidence and, where data are used, the samples are typically 
small and do not tend to measure the counterfactual impact of the programme or effectively model the determinants of the outcomes. However, the more recent examples in the literature documented above include evidence of good practice using counterfactual estimations. Robust evaluation in the area of rural development aims to address monitoring and evaluation by adopting quantitative methods to successfully measure the counterfactual and mixed methods to adequately assess the drivers of sustainable development.

\subsection{Capital infrastructure projects}

When spending on rural and community development is in the form of capital expenditure, some level of ex-post evaluation should ideally be undertaken. However, as in the case of the evaluation of current expenditure, a range of issues arises which suggests that a level of pragmatism will be required in adapting the more rigorous methods of evaluation. This is most easily illustrated by drawing on the Public Spending Code.

Under the Public Spending Code, proposals for capital spending must be presented along with an array of supporting information including ex-ante financial and economic evaluations of project proposals and suggestions for how ex-post evaluation will also be undertaken. The extent of the information required varies with the scale of the proposed projects, but even smaller scale projects require some form of analysis of the likely costs and benefits.

The Code provides guidance on standard techniques, including Cost Benefit Analysis (CBA) which is to be applied in the most formal evaluation processes, typically for larger projects. The main methodological challenges in CBA, when applied ex ante, can be summarised as follows:

- Accurately forecasting all costs, including timelines;

- Forecasting and measuring benefits, including the use of non-market valuations for benefits which are non-monetary;

- The use of an appropriate discount rate to deal with the different timings for the flows of costs and benefits.

The Code also allows for the application of other methods of evaluation, such as multi-criteria analysis (MCA), where the use of a CBA might not be possible.

Turning to the specifics of the ex-post evaluation of capital expenditure in the context of rural and community development, the starting point will be the 
proposals which underlay the decision to award the grant and to undertake the project.

On the assumption that such proposals contained some discussion of costs, it should be possible to assess cost out-turns relative to expectations, including situations where project specifications had to be altered in the light of anticipated cost over-runs.

The question of project benefits is likely to be more complicated. Where CBA has been undertaken ex-ante, thought will have been given to the nature of the likely benefits and to methods of measuring those benefits and expressing them in monetary terms if no market valuations exist. Even where a CBA has not been undertaken, those proposing the project are likely to have been required to describe the nature of possible benefits. For example, if a sports facility has been built, it is likely that the health benefits will have been included in a proposal. At the point of ex-post evaluation, the tasks will be to assess whether such benefits were actually realised and how they might be quantified and aggregated. Mirroring a challenge in the evaluation of current spending, it will also be necessary to assess if any benefits can be linked directly to a given capital project or whether some other initiative in the area played a role.

One key limitation that must be considered is systematic optimism bias. The international literature that considers the evidence on the expected costs and benefits of public infrastructure projects highlights the fact that projects often do not go according to plan and that estimates are often subject to systematic optimism bias. For example, Flyvbjerg et al. (2003) analysed 258 projects from 20 countries covering a range of public infrastructure projects (e.g. rail, bridge, tunnel and road projects) and found that 90 per cent of projects were subject to cost over-runs. In the UK, it is deemed best practice to make an explicit allowance for optimism bias at the project evaluation stage. For example, the UK Department for Transport published a set of guidelines (see Flyvbjerg and COWI, 2004) recommending that a fixed percentage be added to the costs for the purposes of CBA.

\subsection{Enterprise supports}

The evaluation of enterprise supports generally relates to SME assistance and will typically focus on outcome variables related to firm level performance such as employment growth, employment sustainability, business turnover, profitability etc. In order to determine the counterfactual impacts of supports evaluators will, in general, attempt to identify a control group of non-supported firms against which to benchmark the performance of supported enterprises. Evaluations may 
also focus on measuring the differential impacts of different forms of grant assistance on the performance of assisted firms; for example, the relative impact of marketing, capital, R\&D, employment grants, etc. on assisted firm performance (McGuinness and Hart, 2004).

International best practice in evaluating enterprise supports is clearly laid out in well cited publications by Storey $(1998 ; 2000 ; 2003)$ in which he identifies six key stages in evaluating the impact of supports to small businesses. These are also discussed in an Irish evaluation context in Lenihan et al. (2005). Of the six stages, the first three stages relate to effective monitoring, with the final three stages focusing on evaluation. The six key stages to enterprise support evaluation are summarised as follows:

1. Take-up of schemes: This relates to quantifying and profiling the take-up of schemes and might involve examining the distribution of firms taking advantage of supports in terms of their size, sector, ownership type, location etc. This step fulfils an accounting and legal function but has no economic role; the purpose of the step is to ensure that the programme expenditures are consistent with stated programme objectives.

2. Recipients' opinions: In this stage, participating firms are asked their opinions regarding the value of the supports received under the particular assistance programme; for instance, firms in receipt of training supports would be asked if they thought that there was any value in the training that was delivered. Firms are also asked about the effectiveness of the application process for receiving programme supports. Stage 2 can deliver some important insights into the nature of programme access and policy delivery; however, this step will not demonstrate programme effectiveness in terms of achieving set programme objectives related, for example, to aspects of firm performance.

3. Recipient view on the difference made by the assistance: In this stage, recipients are asked if the assistance made any difference to the firm's performance and are, usually, required to quantify the impact in terms of metrics that are relevant to programme goals (employment, turnover, profitability, etc). The problems that arise with this aspect of monitoring are that it is difficult to validate the firms' responses and the responses may also be biased upward. ${ }^{14}$

4. Comparison of the performance of assisted firms with typical firms: In this stage, the performance of assisted firms is compared with non-assisted firms, with the clear inference being that any difference in the outcomes of the two groups can be attributed to the policy intervention. For example, this stage might involve comparing rates of employment 
growth among assisted firms with those of 'typical firms' within the economy. The main drawback with this approach is that assisted firms may not be 'typical' themselves; therefore, the control group of 'typical firms' may not be an appropriate benchmark against which to measure programme impacts.

5. Matching: In this stage, researchers will typically seek out a control group that more readily compares with assisted firms. This matching approach will generally be driven by the objectives of the policy. For instance, if the programme aimed at stimulating growth among new firms, then the matching process would seek to draw a sample of newly registered businesses that, while meeting the criteria for support, did not receive assistance under the programme.

6. Take account of selection bias: In this stage, the researcher applies formal statistical tools such as propensity score matching to try and eliminate any remaining differences in observable characteristics between the control and treatment firms. Any differences observed in the performance of both sets of firms, post selection bias controls, can more confidently be attributed to the influence of the programme.

In many instances, researchers will not typically follow all of the stages, for instance, stage 4 might be omitted in favour of proceeding directly to matching and the implementation of selection controls. However, where possible, the suggested monitoring (stages 1, 2 and 3) should be pursued prior to the formal evaluation exercises (stages 4, 5 and 6), as they can provide valuable additional insights into programme strengths and weaknesses.

In the US, Lipscomb et al. (2018) examine the effects of receipt of business assistance services from the Manufacturing Extension Partnership (MEP) on manufacturing firm performance. They build on two earlier studies by Jarmin (1999) and Ordowich et al. (2012) assessing the impact of MEP services on manufacturing productivity, sales, and employment growth. Lipscomb et al. (2018) extends this body of economic development evaluation studies by using a fuzzy logic matching programme to confirm that MEP data and census data are linked to the correct establishment and by updating the analysis (for the 2002 to 2007 period). The results generally indicate that MEP services have had positive and significant impacts on firm productivity and sales per worker for the 2002 to 2007 period. However, significant productivity differences associated with MEP services are shown by broad sector, with higher impacts shown for the durable goods manufacturing sector. The paper further finds that firms receiving assistance from the MEP are more likely to survive than those that do not receive MEP assistance. 
From an international perspective, Lenihan (2011) argues that enterprise policy is more recently focused on creating an environment to support start-ups and entrepreneurship. Therefore, traditional enterprise evaluation metrics can be viewed as quite narrow given that they focus almost exclusively on private firm impacts, rather than broader societal impacts. Lenihan (2011) further illustrates how Logic Models can be expanded to account for these broader societal impacts.

\subsection{Employment supports}

The evaluation of employment supports, whether focused on self-employment or standard employment, typically involves comparing the rate of employment of supported jobseekers (the treatment group) with a comparison group not in receipt of supports (the control group). There have been numerous examples of this approach in Ireland over recent years. Recent examples of standard counterfactual employment evaluations include Kelly et al. (2019), McGuinness et al. (2014) and Indecon (2013). The evaluation of employment programmes has become much easier in recent years with the development of the Jobseekers Longitudinal Database (JLD) and statistical profiling (O' Connell et al., 2012), which have led to a more accurate control and treatment group identification.

However, many employment supports within the realm of community development target individuals facing more substantial barriers to employment (such as homelessness, physical or mental health problems, addiction issues, language difficulties, etc.). Such supports are termed pre-employment programmes that typically target individuals who are deemed to be further (or furthest) away from the labour market, relative to usual claimants. Relative to more mainstream labour market activation programmes, the evaluation of pre-employment supports is a more complex exercise for a number of reasons. Firstly, it is very difficult to get data on a comparable control group to allow for the estimation of a counterfactual. Secondly, even when an appropriate control group is available, it is likely that the participants in the programme will have a complex and diverse range of needs meaning that employment is far from an immediate realistic prospect for many of them. Consequently, it is unlikely that a quantitative approach alone will be sufficient to capture the effects of such programmes. For this reason, researchers will typically adopt a mixed methods approach, combining analyses of existing administrative data with in-depth surveys with staff and participants in a range of settings.

The publication by the Institute of Employment Studies (Dewson et al., 2000) entitled Guide to Measuring Soft Outcomes and Distance Travelled emphasises the importance of assessing soft outcomes in evaluations that focus on individuals facing particular barriers: 
Hard outcomes such as jobs obtained, numbers of qualifications, and numbers progressing onto further education and training (though useful in some cases), do not show the success of the project as a whole. They are an insufficient indicator of a beneficiary's increased employability. Target groups that are facing multiple barriers to employment may be a long way from being able to acquire a qualification or employment. Consideration of soft outcomes for such groups is a crucial indicator of success. Measuring soft outcomes can also help with the national level evaluation to provide a fuller picture of the impact of the programme as a whole (Dewson et al., 2000).

Such outcomes of interest can be categorised under four headings: key work skills (e.g. teamwork, communication, literacy, timekeeping etc.); attitudinal skills (e.g. motivation, confidence, responsibility, self-esteem etc.); personal skills (appearance, attendance, timekeeping etc); and practical skills (ability to complete forms, manage money, complete a CV etc.). As outlined above, focusing on employment outcomes alone for such a marginalised group may give a misleading picture of programme impact. The ESRI has recently completed a mixed methods study of pre-employment supports delivered under the SICAP programme. ${ }^{15}$ The research combines a counterfactual estimate of immediate employment impacts with case study and survey evidence aimed at identifying the softer impacts of the programme.

\subsection{Amenities}

The evaluation of amenities will vary depending on the goals of the project, the data available and the budget available for evaluation. Amenity projects might include the development of local parks, woodlands, libraries and leisure facilities such as sports centres and swimming pools. The evaluation of amenities usually focuses on the benefits to immediate users and this will generally, but not always, require some primary data collection.

There are several approaches to valuing amenities; the most common approach is the Contingent Valuation Method (CVM), a stated preference method, under which respondents are asked about their willingness to pay (WTP) for amenities. A second approach is to measure revealed preferences (RP), which relies on data from real markets in order to draw conclusions on the value of non-market goods. For example, Tryvainen and Miettinen (2000) use data from house price sales to estimate the value of urban forest amenities in Finland; they found that a one-kilometre increase in distance from an urban forest led to a 5.9 per cent decrease in house prices. Work is currently underway in the ESRI to link amenities 
to tourism visitor numbers and spending in Ireland; this approach also adopts the RP methodology. The Travel Cost Method (TCM), which is based on measuring the costs individuals are willing to incur in order to enjoy an amenity, is a commonly adopted revealed preferences approach used in the literature. The principal aspects of both the CVM and TCM approaches are summarised below:

1. Contingent Valuation Method: This method of valuation centres on respondents to surveys indicating exactly how much they are willing-to-pay (WTP) or willing-to-accept (WTA) in return for the use, or enjoyment, of a particular amenity. The reliance of the technique is highly dependent on the survey approach to describing the hypothetical market and also the questionnaire techniques adopted to measuring WTP and WTA. Open ended questions allow respondents to record any value but may be subject to upward or downward bias; conversely closed questions restrict the range of answers, but the selected range may be inappropriate and also generate a biased result. Consequently, the more common approach is to use dichotomous questions whereby individuals respond Yes or No when asked if they are willing to pay $X$ amount for an amenity; and individuals responding no to a particular amount might then be given another dichotomous question for a lower amount and so on. Nevertheless, all of the valuation approaches may be subject to bias related to the respondents' belief system; respondents may offer an exaggerated price for projects that they believe are worthwhile (warm glow effect) or a depressed (or zero) price for projects that they disapprove of (protest bid).

2. Travel Cost Method: This approach is based on measuring the amount of time and expense that people incur in order to visit and enjoy a particular amenity. This approach is generally based on survey data collected from visitors to sites; information typically captured includes the number of visits to the amenity, time spent travelling and a range of socio-economic control variables (age, gender, education, occupation etc.). The data captured in these surveys is generally modelled using one of two econometric approaches ( $a$ ) the Poisson model and ( $b$ ) the negative binomial model. The negative binomial model is generally preferred as it can be used to estimate a demand curve for a given amenity and the level of consumer surplus.

\subsection{Summary}

Based on the analysis of DRCD programmes and expenditure in this report, six main areas of activity were identified for review of international approaches to measurement and evaluation. These were (i) community development, (ii) rural development, (iii) capital infrastructure projects, (iv) enterprise supports, (v) employment supports, and (vi) amenities. 
The review of international approaches revealed that the methodological approaches for evaluation of some areas such as capital infrastructure projects is developed and relatively straightforward, while evaluating the impacts of other areas such as community and rural development is much more complex. Interestingly, a number of recent examples in the international literature use a range of estimation approaches to measure counterfactuals of rural development programmes. In contrast, the evaluation methods related to capital infrastructure projects, enterprise supports, employment supports and amenity projects are long-standing and well developed. The most common evaluation approaches used internationally have been summarised in this chapter. 


\section{Evaluation approaches in the Irish context}

\subsection{Introduction}

Chapter 3 identified the main international methodologies used for evaluation of six key areas of DRCD's programme activity. In this chapter these evaluation methodologies are discussed in an Irish context. Examples of existing evaluations across each of these key areas are examined, as well as the extent to which methodological approaches and the existing data infrastructure compare to the international approaches identified in Chapter 3.

\subsection{Community development}

The Government's five-year strategy to support the community and voluntary sector Sustainable, Inclusive and Empowered Communities was published in 2019. Six objectives are identified in the strategy; (i) a thriving community and voluntary sector, (ii) strengthened partnership between Government and the community and voluntary sector, (iii) community supports underpinned by societal value and community need (iv) resilient communities empowered to meet emerging challenges, ( $v$ ) empowered communities informing and shaping responses to their needs, and (vi) a thriving volunteer culture. The strategy sets a general direction of travel for Government policy in community development but states that it is part of a suite of initiatives led by DRCD and supporting not-for-profit organisations in the community development, local development, community and voluntary sectors, and social enterprises.

The ESRI has already published a substantial amount of research surrounding the difficulties associated with evaluating community development programmes. This research mainly focused on SICAP which is one of the largest areas of community development spending by DRCD. As discussed earlier in this report, counterfactual evaluations cannot be effectively carried out for community development programmes (see Whelan et al., 2019 for more information). Therefore, we consider some key metrics that might be included in programme Logic Models and distance travelled tools relevant to specific programmes in Ireland. ${ }^{16}$ We also suggest potential themes under which more qualitative evidence and data might be collected. It is important to note that while we treat 'rural development' as a separate category in our analysis in this report, much of this spending is community

16 A distance travelled tool approach has been put in place for the Social Inclusion and Community Activation Programme (SICAP), funded by the Department and delivered through Pobal. 
development but within a rural context and therefore many of the principles of community development evaluations also apply.

In terms of methodological approaches, programme expenditure that is directed at a specific location allows for the possibility of data for baseline quality of life metrics and/or a distance travelled tool to be collected in the treatment area and also in similar, perhaps neighbouring, areas not receiving this funding. This will allow for effective monitoring of the extent to which individuals' general perceptions of life quality - as measured by the distance travelled tool, and specific quality of life metrics (potentially available through survey information or administrative data) - have changed in the targeted area relative to the comparison area. However, Whelan et al. (2019) point out that while this comparison will be informative with respect to programme impacts, it will not be possible to measure direct causal effects stemming from the programme.

ESRI research indicates that the development of an approach similar to the Logic Model would be helpful in terms of monitoring progress of community development programmes such as SICAP (an example is outlined in Appendix A of this report), where the specified processes and outcomes are linked precisely to its goals. It is important to have such a systematic framework in place in terms of monitoring; however, monitoring and the evaluation of causal influences are different concepts. Tools such as the Logic Model provide a useful framework for monitoring interventions but are not a means of measuring causal relationships. Theory of Change includes the specification of causal mechanism and therefore transforms Logic Models. While still not necessarily measuring causal relationships, it can help to provide supporting evidence for them.

Examples of quality of life metrics that could be considered for evaluation of community development include the percentage of people living in poverty (from the census and HP Deprivation Index), crime rates (from Department of Justice), local unemployment rate (from DEASP), number of local community group and community activists (from Pobal), membership of clubs and community associations (from Pobal), and mean and medium incomes (from the Census). These metrics could be used for comparison with similar non-treated areas and also with a logic framework to allow for the tracking of changes within the area over time.

Qualitative information could be collected through case studies and workshops on themes relevant to the programme objectives such as improvements in the general level of amenities, crime reduction, and general community well-being. Thematic reports could also be compiled on any specific area of community level capacity 
relevant to a programme. Qualitative thematic reviews could be designed and validated by an appropriate external body to ensure consistency and independence. The inclusion of more qualitative measures can allow for a more in-depth analysis of the quality of the processes and outcomes involved, and furthermore allow for the context within which groups operate to be reflected in the general assessment. The systematic extrapolation of good practice from intermittent thematic reports and/or a full review of the end-of-year reports was proposed by Whelan et al. (2019) to provide a unified view of changes that are occurring in the areas of community development as a consequence of SICAP and other community development programmes.

It is important to note that a challenge of such bottom-up approaches to the evaluation of SICAP, and other community development programmes, is that subjectivity bias can arise when stakeholders play a central role in the monitoring and assessment processes. ${ }^{17}$ To ensure appropriate assessment, intermittent independent monitoring, preferably by a third party, can be used with a combination of assessment approaches, i.e. qualitative and quantitative analysis of key metrics (informed by the Logic Model approach) to obtain a balanced and objective view of progress.

\subsection{Rural development}

The number of publicly available evaluations of rural development programmes in an Irish context is limited. A mid-term evaluation of Ireland's Rural Development Programme (2014-2020) was published by Indecon in 2019. The Rural Development Programme (RDP) is a component of the Common Agricultural Policy (CAP) and has a budget of $€ 4$ billion for the 2014 to 2020 period, $€ 2.2$ billion of which is provided by the EU. The RDP has six priority areas: (i) fostering knowledge transfer and innovation in agriculture, forestry and rural areas; (ii) enhancing the viability/competitiveness of farms and all types of agriculture; (iii) promoting food chain organisation and risk management in agriculture; (iv) restoring, preserving and enhancing ecosystems dependent on agriculture and forestry; (v) promoting resource efficiency and supporting the shift toward a low-carbon and climate resilient economy in the agriculture, food and forestry sectors; and (vi) promoting social inclusion, poverty reduction and economic development in rural areas.

Indecon's evaluation contains a range of methodological evaluation approaches to measuring impact, including qualitative information collected through case studies and consultations, the collection of survey data, counterfactual econometric

17 Participatory approaches to monitoring and evaluation, where professional evaluators together with stakeholders are involved and the approach is implemented according to good practice, are conscious of and take steps to counteract subjectivity bias. 
models and indicator analysis. In order to estimate the counterfactual impact of the RDP, Indecon (2019) makes use of the BIO-ECONOMY input-output model, developed by Teagasc, NUIG and the Marine Institute, to estimate that RDP expenditure generated 4,881 jobs nationally of which 4,178 were created in rural areas. The BIO-ECONOMY model generates a range of sectoral multipliers that allow for the total impacts of project expenditure to be estimated. Using the multipliers, Indecon (2019) estimated that the overall impact of the RDP over the period 2014-2018 was €4.24 billion.

There are also evaluation and reporting requirements associated with the LEADER programme, which is a sub-component of the RDP, that add to the national capacity in this area. For the 2014 to 2020 period, the LEADER programme has a budget of $€ 250$ million in grant supports for rural communities and businesses. DRCD acts as programme manager for LEADER in Ireland. The programme is administered at a local level by 29 Local Action Groups (LAGs) that are made up of representatives from the community, private and public sectors. Grants are provided under three priority schemes: (i) Economic development, enterprise development and job creation; (ii) Social inclusion, and (iii) Rural development. LAGs are responsible for selection projects to be funded under the programme and selected projects must be aligned to each LAG five-year Local Development Strategy.

DRCD is supported in its management role by Pobal, which delivers a number of aspects of the programme including the performance and monitoring of LEADER funded projects. Performance and monitoring data are collected through a bespoke ICT system. The LEADER programme impacts are assessed through the use of common indicators that are collected across all EU Member States. Within the ICT system used for recording these indicators the primary objective of each project must be selected from a pre-populated list of objectives applicable to the specific LDS area. The project target groups ${ }^{18}$ are selected within the system and the type of projects is also stipulated. ${ }^{19}$

Prior to the commencement of any project, the anticipated outcomes must be outlined. Data are then collected at the end of the project, which will be related to the project objectives. Examples of end-of-project outcomes collected include: the number of jobs created; the number of people trained and the duration of any training; the number of people in disadvantaged, or hard to reach communities,

18 The target groups include children, homeless individuals, fishermen, farmers, islanders, tenants, NEETS, lone parents, migrants, Roma, the unemployed, SMEs, Travellers, women and young people.

19 The five project type categories include: (i) Analysis and development, (ii) Capital, (iii) Large scale project, and (iv) Marketing and (v) Training. 
benefiting from the projects or accessing services; and the number of visitors to tourism projects.

The impacts of LEADER spending are based around a common EU-wide monitoring framework. ${ }^{20}$ But there is little evidence of attempts within the guidelines to measure counterfactual outcomes or measure impacts qualitatively. Furthermore, we could find no published monitoring reports on LEADER expenditure in Ireland and the only publicly available analysis appears to be contained within synthesis reports aimed at assessing the impacts of the programme at an EU-wide level. Nevertheless, the data infrastructure developed as a result of LEADER monitoring requirements is likely to be an important resource for any formal attempts to measure the counterfactual impact of LEADER interventions in Ireland.

Finally, it is worth noting the potential official statistics could have for monitoring and evaluation of rural projects. In 2019, the Central Statistics Office (CSO) identified a six-way urban/rural categorisation of Ireland that could be useful in this regard (see Figure 4.1). Urban areas were sub-divided into three categories (cities, satellite urban towns, and independent urban towns) based on the proportion of people in employment in cities. Rural areas were also subdivided into three categories (rural areas with high urban influence, rural areas with moderate urban influence and highly rural/remote areas) based on the proportion of usual residents in employment in urban areas. Incorporating such information into evaluation measures could be an important future development.

20 See Synthesis of mid-term Evaluations of LEADER+ Programmes, published by the European Union in November 2018. For more information, see https://ec.europa.eu/info/food-farming-fisheries/key-policies/common-agriculturalpolicy/cmef/rural-areas/synthesis-mid-term-evaluations-leader-programmes_en. 
TABLE 4.1 CSO SIX-WAY URBAN/RURAL CATEGORISATION, 2019

\begin{tabular}{|c|c|c|}
\hline & Type & Definition \\
\hline \multirow{3}{*}{$\begin{array}{l}\text { Urban } \\
\text { areas }\end{array}$} & Cities & $\begin{array}{l}\text { Towns/ settlements with populations greater than 50,000 using Census } 2016 \\
\text { definitions / breakdowns }\end{array}$ \\
\hline & $\begin{array}{l}\text { Satellite Urban } \\
\text { Towns }\end{array}$ & $\begin{array}{l}\text { Towns / settlements with populations between } 5,000 \text { and } 49,999 \text {, where } 20 \text { per } \\
\text { cent or more of the usually resident employed population's workplace address } \\
\text { is in 'cities' }\end{array}$ \\
\hline & $\begin{array}{l}\text { Independent } \\
\text { Urban Towns }\end{array}$ & $\begin{array}{l}\text { Towns / settlements with populations between 5,000 and 49,999, where less } \\
\text { than } 20 \text { per cent of the usually resident employed population's workplace } \\
\text { address is in 'cities' }\end{array}$ \\
\hline \multirow[t]{3}{*}{$\begin{array}{l}\text { Rural } \\
\text { Areas }\end{array}$} & $\begin{array}{l}\text { Rural areas } \\
\text { with high urban } \\
\text { influence }\end{array}$ & $\begin{array}{l}\text { Rural areas (themselves defined as having an area type with a population less } \\
\text { than 1,500 persons, as per Census 2016) are allocated to one of three sub- } \\
\text { categories, based on their dependence on urban areas. Again, employment } \\
\text { location is the defining variable. The allocation is based on a weighted } \\
\text { percentage of resident employed adults of a rural meshblock who work in the } \\
\text { three standard categories of urban area (for simplicity the methodology uses } \\
\text { main, secondary and minor urban area). The percentages working in each urban } \\
\text { area were weighted through the use of multipliers. The multipliers allowed for } \\
\text { the increasing urbanisation for different sized urban areas. For example, the } \\
\text { percentage of rural people working in a main urban area had double the impact } \\
\text { of the same percentage working in a minor urban area. The weighting } \\
\text { acknowledges the impact that a large urban centre has on its surrounding area. } \\
\text { The adopted weights for: } \\
\text { - Main urban areas is } 2 \\
\text { - Satellite urban communities is } 1.5 \\
\text { - } \quad \text { Independent urban communities is } 1 \\
\text { The weighted percentages are divided into tertials to assign one of the three } \\
\text { rural breakdowns }\end{array}$ \\
\hline & $\begin{array}{l}\text { Rural areas with } \\
\text { moderate urban } \\
\text { influence }\end{array}$ & As above \\
\hline & $\begin{array}{l}\text { Highly rural / } \\
\text { remote areas }\end{array}$ & As above \\
\hline
\end{tabular}

Therefore, in summary, while there is somewhat limited evidence of monitoring and evaluation within an Irish context, the available information would seem to suggest that Ireland is relatively well equipped, in terms of both data infrastructure and methodological tools. The availability of the BIO-ECONOMY input-output model is an important asset that allows for the measurement of counterfactual impacts of large-scale rural investment programmes. The mandatory monitoring data, collected for EU programmes such as LEADER, also constitute important assets that could, arguably, be more heavily utilised for evaluation purposes. Finally, the refinement of different measures of rurality within the official statistical framework is also a positive development in the context of monitoring and evaluation capacity. 


\subsection{Capital infrastructure projects spending}

Despite the existence of a number of potential methodologies for evaluating capital projects (such as econometric modelling, input-output methods, multiplecriteria decision analysis - MCDA), CBA remains the dominant methodological approach both in Ireland and internationally. Morgenroth (2011), in a comprehensive review of capital evaluation approaches, points out that CBA requires the specification of a number of critical parameters including expected costs, benefits and the discount rate. Morgenroth (2011) finds no evidence of systematic optimism bias in an Irish context, however, he does make a number of recommendations related to the appropriate CBA discounting methods. He argues that the discount rates used to assess public capital projects in Ireland are typically too low and do not fully take account of risks associated with the rate of return. Furthermore, the author suggests that all projects should be measured against an alternative investment, as the use of 'do nothing comparators' support the selection of projects where any positive rate of return can be demonstrated. The demonstration of a positive rate of return does not, in its own right, equate to an optimal use of public resources.

It is difficult to find any evaluations of capital spending projects within the recent literature. Morgenroth (2009) indicates that job creation typically constituted a principal benefit of capital spending within the CBA framework. In their mid-term review of the 2000-2006 National Development Plan (NDP), FitzGerald et al. (2003) estimate the cost per job created associated with a number of initiatives funded under the NDP's Regional Operational Schemes. Morgenroth (2014) points out that while CBA should be carried out before any planned capital or infrastructural investment, it is necessary for the analysis to be updated on an ongoing basis to reflect changing circumstances that might occur during the investment implementation stage. Ongoing checks to ensure that quality standards are maintained during the construction stage are also important. As examples of ineffective capital investment Morgenroth (2014) cites the Western Rail Corridor and a school building programme. The author argues that the creation of a register listing national capital stock (and its condition) would be beneficial in informing the need for capital investments; such lists exist in Northern Ireland and the UK. A detailed understanding of existing public capital stock will assist with the identification of investment needs and gaps in existing provision.

In a study of planned rail investments for the Greater Dublin Area (GDA), Ustaoglu et al. (2016) argue that traditional CBA approaches to measuring the potential gains from capital investments are problematic as they cannot capture all impacts of the investment. Some costs and/or benefits of investments are difficult to monetise in terms of the social and environmental impacts. Furthermore, with respect to the Metro North investment, Ustaoglu et al. (2016) argue that the 
projected capital costs, and other parameters included in the CBA framework, may have been impacted by estimation bias. The authors show that, under various CBA evaluations, the Metro North investment was not viable over a 35-year period.

A more recent debate over the effectiveness of capital spending evaluation approaches related to the building of the new National Children's Hospital (NCH), where an independent review was conducted by PwC (PwC, 2019). In 2017, the cost for building the $\mathrm{NCH}$ and two satellite centres was €983 million; however, by 2018 the cost had risen by $€ 450$ million to $€ 1.43$ billion. PwC concluded that the cost over-run was a consequence of significant failures at particular stages of the project. At the budgeting and planning stage risks were understated and there was a failure to secure a guaranteed maximum price (GMP). Furthermore, the review found that there had been a failure to comply with the Public Spending Code and to undertake a revised cost benefit analysis following a series of cost increases. The PwC (2019) report also highlighted serious failings in project governance and execution, which also contributed to the substantial financial over-run.

\subsection{Enterprise supports}

There have been relatively few programme evaluations of enterprise or SME supports in Ireland in the published literature. Of the studies that do exist in terms of SME supports, the one most consistent with international best practice was an analysis of small firm development and grant assistance in both Northern Ireland and the Republic of Ireland by Roper and Hewitt-Dundas (2001). The data for the study came from a sample of firms selected in both jurisdictions with the objective of measuring the impact of various forms of grant assistance on a number of outcome variables including turnover, profitability and employment growth. The Roper and Hewitt-Dundas (2001) analysis, after controlling for potential selection bias, found that grant assistance had no impact on turnover or profitability growth but did boost employment growth.

Across a number of State programmes, assistance is provided to support Social Enterprises and SMEs. ${ }^{21}$ Although the objectives of such programmes can be wide ranging, the impacts of such spending can be measured both quantitatively and counterfactually. The outcome metrics against which such programmes to support SMEs are typically assessed include the number of business start-ups, the sustainability of new enterprises, the employment growth of assisted enterprises and other performance indicators such as turnover and profitability. 
The programme of evaluation of supports provided by State Enterprise agencies, conducted by DJEI (2015) is one such example. This study was conducted across three thematic areas including: Start Up and Entrepreneurship (2012); Research, Development and Innovation (2012-2013); and Business Development (20132014). The framework used for these evaluations was the Programme Logic Model. Quantitative findings were predominately expressed in terms of additional jobs or exports that could be directly attributed to participation in the programme. Cost benefit analysis was also undertaken where data permitted. Qualitative findings were used to further explain how and why the programmes helped generate behavioural additionality (e.g. capability building, leadership, increased collaboration, ambition, resilience, improved working environments). In relation to impact assessment, DJEI (2015) reported that where control group analysis was possible, the evaluation found evidence that supported firms were more resilient over the period of the recession, achieved higher growth levels in employment and exports, realised greater productivity improvements, and experienced higher survival rates.

Furthermore, DPER (2017) uses a Spending Review approach and focuses on the criteria of rationale and efficiency to evaluate the supports offered by Enterprise Ireland. This approach has a number of limitations, including the level of potential self-selection bias. To assess this in a more robust way, DPER (2017) reports the necessity for an anonymised dataset of the broader cohort of non-supported internationally trading companies in the Irish economy to be used as a control group. They state that where packages of supports are provided it is extremely difficult to evaluate which supports are more effective than others. However, a new Client Engagement Model has been designed by Enterprise Ireland (EI). It is suggested that this new model may facilitate better evaluation, but only if it is supported by both the collection of robust data by EI and the development of anonymised data on the broader cohort of non-supported firms.

In the Irish context, existing administrative data sources do not easily allow for the identification and measurement of the performances of social enterprises (either assisted or unassisted) at local level. Therefore, while in theory we could compare and measure various metrics within an assisted enterprise and potentially within areas where there is no uptake of these supports, in order to measure the counterfactual impact of the assistance, the reality is that this would be very difficult within an Irish context currently. There are, however, a number of options available. If the individuals receiving supports were previously unemployed and identifiable by their PPSN number within the Live Register database held by DEASP, this would allow researchers to match assisted individuals with comparable unassisted claimants to measure the extents to which programme support reduce the probability of being unemployed at some future point (e.g. 18 months, 24 months, 36 months). As the Jobseekers Longitudinal Database (JLD) has a 
longitudinal component this could be done almost immediately using historical data.

Furthermore, it should be possible to measure the differential impact of various types of assistance administered under the programme on both the performance and sustainability of assisted enterprises. For example, an assessment could examine the differential impacts of supports - such as capital, marketing, employment, IT, education supports etc. - on the employment growth, profitability and sustainability of assisted enterprises (see Roper and Hewitt-Dundas, 2001). Therefore, while administrative data are lacking in this area, it is highly advisable that metrics related to performance and grant assistance are routinely collected to facilitate such evaluations (McGuinness and Hart, 2004).

These assessments could be further supplemented with qualitative research involving workshops and case studies focused on measuring the wider benefit of enterprise supports on metrics related to community well-being and also softer progression metrics of individuals employed as a result of supports such as selfconfidence, communication skills, self-worth, etc.

\subsection{Employment supports}

Since 2010 there has been a steady stream of studies published using international approaches to measure the impact of employment supports in Ireland. McGuinness et al. (2011) use treatment and control groups, combined with propensity score matching, to evaluate impacts of employment supports delivered under the National Employment Action Plan (NEAP). They found that substantial failings in NEAP structures actually reduced participants' employment probabilities by 17 per cent relative to a control group. Using a similar approach, McGuinness et al. (2014) estimated the impacts of training supports to the unemployed and found strong positive impacts for job search courses and medium to high-level specific skills training. Kelly et al. (2015) again use a control and treatment approach, combined with matching, to measure the employment outcomes of jobseekers accessing Back to Education Allowance (BTEA) supports. The authors found that the programme substantially reduced programme participants' probabilities of entering employment. Kelly et. al. (2019) use Difference-in-Differences methods to evaluate changes to the structure of unemployment activation services in Ireland ${ }^{22}$ and found little evidence of any short-run impacts. DEASP (2019) used a matching approach to measure the impact of assistance provided to long-term claimants under the JobPath initiative and found that the programme increases exits to employment by approximately 20 per cent compared to a control group. Finally, Whelan et al. (2020) uses mixed methods approaches to estimate the 
counterfactual impact of one-to-one supports provided to jobseekers under the SICAP programme; the study also uses qualitative approaches to identify the underlying processes driving the observed counterfactual impact.

\subsection{Amenities}

There is not a vast literature evaluating the impact of amenities in Ireland. However, what does exist appears consistent with international methodological best practice. Hynes and Hanley (2006) use the Contingent Valuation Method (CVM) approach to measure the Willingness to Pay (WTP) for using a farm commonage site in County Galway. Hynes and Hanley (2006) use revealed preferences via the Travel Cost Method (TCM) approach to investigate the value of urban woodland space in Ireland. They find that average willingness to pay to visit an urban forest in Galway was $€ 12.33$ of which direct travel costs amounted to $€ 7.36$ with the balance equating to a consumer surplus of $€ 4.97$. More recently, Manton et al. (2016) use the TCM to measure the impact of Greenways in Ireland. They found that such amenities generate an average spend per Greenway user day of $€ 47$, the majority of which related to spending on food and accommodation. The authors estimate that the consumer surplus retained by Greenway users was 77 per cent. However, there is some debate around the relative merits of the various approaches, while we would expect WTP (measured using the CVM approach) and TCM estimates to be closely aligned, Mayor et al. (2007) in a study of the recreational use of Irish forests, found that the approaches produce diverging results. Mayor et al. (2007) found that WTP estimates were clustered around the IRf1 value whereas TCM estimates ranged from IRf2.38 to IRf5.95 depending on the sample used.

\subsection{Summary}

This chapter examined the use of the international evaluation methodologies in an Irish context across the six main areas of DRCD activity: (i) community development, (ii) rural development, (iii) capital infrastructure projects, (iv) enterprise supports, (v) employment supports, and (vi) amenities.

With respect to the evaluation of community development programmes in Ireland, there exists a rich quantitative and qualitative data framework that will enable effective monitoring and impact measurement through a range of tools including the Logic Model framework, distance travelled tools and thematic qualitative reports. ${ }^{23}$ Counterfactual evaluation is not practical due to the range of confounding factors (identified in Chapter 3). Internationally, there are recent

23 A mixed methods approach is currently being used for SICAP including the recent introduction of My Journey: Distance Travelled Tool, and the use of case study reports which supplement hard data (e.g. numbers employed post-SICAP supports) gathered under the programme. 
examples of a range of estimation approaches being applied to measure counterfactuals of rural development programmes. Within Ireland, while there are relatively limited examples of rural project evaluations, the studies, modelling tools and data infrastructure that currently exist are promising. The methodologies are well understood within an international context for the evaluation of capital infrastructure programmes and the regulatory frameworks also appear well established through government guidelines. Nevertheless, some clear weaknesses have been identified at a national level. Evaluation approaches in the areas of both employment supports and amenities, while relatively limited in number, appear to meet international best practice standards. However, relative to other countries, there is a lack of counterfactual evaluation in the area of enterprise supports. 


\section{CHAPTER 5}

\section{Summary and conclusions}

\subsection{Introduction}

This report is the first report to be published under a Research Programme between DRCD and the ESRI. The aim of this Research Programme is to help inform policymaking decisions of the Department. DRCD was established in 2017 and has led Government responsibility for rural and community development in Ireland. In 2019 DRCD gross expenditure was $€ 291$ million, of which $€ 153$ million was current expenditure and $€ 138$ million capital expenditure. ${ }^{24}$ An examination of programme areas funded by DRCD in Chapter 2 of this report shows that the Department undertakes a diverse range of activities. However, six key areas of common activity were identified across 20 programmes of expenditure. These are, (i) community development, (ii) rural development, (iii) capital infrastructure, (iv) enterprise supports, (v) employment supports, and (vi) provision/development of amenities. The majority of Department expenditure is targeted towards programmes with either rural and/or community related objectives, and so most emphasis in this report was placed on these areas. A summary of the findings in these areas is outlined below followed by the conclusions.

\subsection{Community development}

The existing research has highlighted a number of major barriers to measuring the impacts of community development spending within a counterfactual framework. Furthermore, there exists no convincing evidence that these difficulties have been overcome within any international studies. The literature suggests that there are several frameworks such as the Logic Model which can potentially be used to monitor the impact of community development programmes. These frameworks involve defining programme objectives, inputs, processes and outcome variables. Whelan et al. (2019) have conducted extensive research on community development in Ireland through an examination of DRCD's Social Inclusion and Activation Programme (SICAP). They suggest that there is a rich quantitative and qualitative data framework that will enable effective monitoring and impact measurement through a range of tools including the Logic Model framework, distance travelled tools to measure soft outcomes and thematic qualitative reports. 


\subsection{Rural development}

Many of the difficulties and the methodologies for examining community development are relevant to rural development but there is some evidence that empirical based counterfactual evaluation methodologies can be more readily applied in this area (see Michalek et al., 2020 and Gertler et al., 2016). In terms of rural development metrics, effective monitoring techniques are also a relevant tool for measuring impacts in this area. Some metrics have also been developed specifically for rural development analysis. For example, a Rural Development Index (RDI) based on socio-economic, environmental, infrastructural and administrative indicators has been used to measure overall rural development and quality of life in regions of EU countries. Broader non-programme specific data could be used to monitor development of rural areas, but this does not allow for a causal link to be established to specific programmes. Publicly available evaluations of rural development programmes in Ireland are limited in number. But the tools (data infrastructure and modelling) to undertake such analysis appear promising. The BIO-ECONOMY input-output model, developed by Teagasc, NUIG and the Marine Institute, has been used to measure counterfactual impacts of large-scale rural investment programmes such as the RDP. Furthermore, a substantial amount of monitoring data exist which are important for future evaluations e.g. data collected under EU programmes such as LEADER. Developments in official statistics such as the CSO's publication of a six-way urban/rural categorisation of Ireland is also useful as it could potentially be used to analyse metrics on a geographical basis e.g. rural areas.

\subsection{Capital infrastructure projects}

While the methodologies used for capital projects are well understood within an international context, and regulatory frameworks well established through government guidelines, weaknesses have been identified at a national level. In particular, the appraisal, implementation and governance approaches applied to large scale capital projects such as Metro North and the National Children's Hospital appear to have fallen below the standards of international best practice. There can also be challenges to undertaking the methodologies such as cost benefit analysis in terms of accurate forecasting of costs and/or timelines, measuring benefits (including those that are non-monetary), the use of an appropriate discount rate and systematic optimism bias. In a rural and community development context, the costs and benefits outlined in project proposals can be compared to the out-turn to examine whether expectations have been realised. However, it can be difficult to establish whether the benefits are directly attributable to the project itself. 


\subsection{Enterprise supports}

The evaluation of enterprise supports usually focus on outcome variables related to firm-level performance such as employment, profitability, turnover, etc. Assessment of counterfactual impacts attempts to benchmark the performance of supported enterprises against non-supported enterprises. There have been few published studies in Ireland, but they have been consistent with international approaches. However, examining Ireland relative to other countries, there is a lack of counterfactual evaluation in the area of enterprise supports. This may be due, in part, to the lack of administrative, or survey, data that would facilitate such analysis. Potential options could involve matching enterprises receiving supports with similar enterprises who received none in order to measure the extent to which supports impacted performance across various dimensions. It should also be possible to measure the impact of various types of assistance on the performance and sustainability of assisted enterprises e.g. employment growth, profitability and sustainability of assisted enterprises. This could be supplemented with qualitative research focused on measuring the wider benefit of enterprise supports on metrics related to community well-being and softer progression metrics of individuals employed.

\subsection{Employment supports}

There are many studies published in Ireland using international approaches to measure the impact of employment supports. Evaluation approaches within these studies overall appear to meet international best practice standards. The evaluation of employment supports generally involves comparing the rate of employment of supported jobseekers with a comparison group not in receipt of supports. However, hard outcomes alone such as jobs obtained may not show the success of the programme as a whole especially when considering those who may be furthest from the labour market. Community development programmes often target individuals facing more substantial barriers to employment (such as homelessness, physical or mental health problems, addiction issues, language difficulties, etc.). Such supports are more difficult to formally evaluate due to the problems of finding an appropriate control group. Mixed method (qualitative and quantitative) approaches have been used by Whelan et al. (2020) to estimate the counterfactual impact of one-to-one supports provided to jobseekers under SICAP. Furthermore, the assessment of soft outcomes such as those measured through distance travelled tools can provide additional insights.

\subsection{Amenities}

Evaluation of amenities generally requires primary data collection and primarily focuses on the benefits to immediate users. The evaluation of amenity projects varies considerably depending on the goals of the project, the data available/ collected and the budget available for evaluation. The most common approaches 
to valuing amenities are stated preference methods, such as the Contingent Valuation Method (CVM), where respondents are asked about their willingness to pay (WTP) for amenities; and revealed preferences methods, such as the Travel Cost Method (TCM), which relies on data from real markets in order to draw conclusions on the value of non-market goods. There is not a lot of literature evaluating the impact of amenities in Ireland, but it is consistent with international best practice. For example, the TCM has been used to measure the impact of Greenways in Ireland in Manton et al. (2016).

\section{$5.8 \quad$ Conclusions}

A review of international approaches in key areas of DRCD activity has revealed that the methodological approaches for evaluation of some areas such as capital infrastructure projects is developed and relatively straightforward, while evaluating the impacts of in other areas such as community and rural development is much more complex. However, monitoring and evaluation of DRCD programmes can be further enhanced through mixed methods approaches (including quantitative and qualitative techniques), combined with improvements in the type and consistency of data collected. This would further expand the opportunities to more formally evaluate or measure robust counterfactual impacts particularly in terms of rural development projects. Non-programme specific data can be used to supplement this approach as a means to further monitoring impacts.

With respect to the evaluation of community development programmes in Ireland, there is a rich quantitative and qualitative data framework that will enable effective monitoring and impact measurement through a range of tools including the Logic Model framework, distance travelled tools and thematic qualitative reports. Internationally, there are recent examples of a range of estimation approaches being applied to measure counterfactuals of rural development programmes. Within Ireland, while there are relatively limited examples of rural project evaluations, the studies, modelling tools and data infrastructure that currently exist are promising. The methodologies are well understood within an international context for the evaluation of capital infrastructure programmes and the regulatory frameworks also appear well established through government guidelines. Nevertheless, some clear weaknesses have been identified at a national level. Evaluation approaches in the areas of both employment supports and amenities, while relatively limited in number, appear to meet international best practice standards. However, relative to other countries, there is a lack of counterfactual evaluation in the area of enterprise supports. The next stage in the research will involve the identification and analysis of appropriate key indicators for monitoring of rural and community development. 


\section{REFERENCES}

Abreu, I., J.M. Nunes and F.J. Mesias (2019). 'Can Rural Development Be Measured? Design and Application of a Synthetic Index to Portuguese Municipalities', Social Indicators Research, 145(3), 1107-1123.

Bakucs, Z., I. Fertő and Z. Benedek (2019). 'Success or Waste of Taxpayer Money? Impact Assessment of Rural Development Programs in Hungary', Sustainability, 11(7), 2158.

Barr, A. and S. Hashagen (2000). ABCD handbook: a framework for evaluating community development. London: Community Development Foundation.

Barr, A. and J. Dailly (2007). LEAP step-by-step: an introductory guide to the LEAP framework (2nd ed.), London: Community Development Foundation.

Bartova, L. and J. Hurnakova (2016). 'Estimation of farm investment support effects: A counterfactual approach', in Proceedings of the International Scientific Conference Quantitative Methods in Economics: Multiple Criteria Decision Making XVIII, pp. 19-24.

Bia, M. and A. Mattei (2008). 'A Stata package for the estimation of the dose-response function through adjustment for the generalized propensity score', Stata Journal: Promoting Communications on Statistics and Stata, 8(3), 354-373. doi: 10.1177/1536867X0800800303.

Boyatzis, R. (1998). Transforming qualitative information: Thematic analysis and code development. Thousand Oaks, CA: Sage.

Braun, V. and V. Clarke (2006). 'Using thematic analysis in psychology', Qualitative Research in Psychology, 3, 77-101. doi:10.1191/1478088706qp063oa.

Buckley, C., T.M. van Rensburg and S. Hynes (2009). 'Recreational demand for farm commonage in Ireland: A contingent valuation assessment', Land use policy, 26(3), 846-854.

Caliendo, M. and S. Kopeinig (2008). 'Some practical guidance for the implementation of propensity score matching', 22(1), 31-72.

Card, D. (1995). 'Using Geographic Variation in College Proximity to Estimate the Return to Schooling', in Christofides, L.N., K.E. Grant and R. Swidinsky (Eds.), Aspects of Labour Market Behaviour: Essays in Honour of John Vanderkamp. Toronto: University of Toronto Press.

Castaño, J., M. Blanco and P. Martinez (2019). 'Reviewing Counterfactual Analyses to Assess Impacts of EU Rural Development Programmes: What Lessons Can Be Learned from the 2007-2013 Ex-Post Evaluations?', Sustainability, 11(4), 1105.

Darmody, M. and E. Smyth (2018). The goals and governance of the Social Inclusion and Community Activation Programme (SICAP) 2015-2017: a mixed methods study, Research Series No. 68, Dublin: The Economic and Social Research Institute.

DEASP (2019). Working paper: 'Evaluation of JobPath outcomes for Q1 2016 participants'. Dublin: Department of Employment Affairs and Social Protection. 
Dewson, S., J. Eccles, N.D. Tackey and A. Jackson (2000). Guide to measuring soft outcomes and distance travelled, Brighton, UK: Institute of Employment Studies, http://www.employabilityinscotland.com/media/83581/guide-to-measuringsoftoutcomes-distance-travelled.pdf. Accessed on 1 March 2020.

DJEl (2015). Evaluations of State Supports for Enterprise, Synthesis Report and Conclusions. https://enterprise.gov.ie/en/Publications/Publicationfiles/Evaluations-of-State-Supports-for-Enterprise-Synthesis-Report-andConclusions.pdf.

DPER (2017). An Assessment of the Rationale, Efficiency and Targeting of Supports in Enterprise Ireland. https://igees.gov.ie/wp-content/uploads/2015/02/AnAssessment-of-the-Rationale-Efficiency-and-Targeting-of-Enterprise-Supportsin-Ireland.pdf.

DRCD (2019). Sustainable, Inclusive, and Empowered Communities: A five-year strategy to support the community and voluntary sector in Ireland, 2019-2024. https://assets.gov.ie/26890/ff380490589a4f9ab9cd9bb3f53b5493.pdf.

DRCD (2018). Realising Our Rural Potential - Action Plan for Rural Development. https://assets.gov.ie/2715/131118093828a9da81a7a12b4f85aad3260c4f4bd80c.pdf.

DWP Department for Work and Pensions (2003). A Practical Guide to Measuring Soft Outcomes and Distance Travelled: Guidance Document. Cardiff: Welsh European Funding Office.

EENRD (2014). Capturing the success of your RDP: Guidelines for the Ex-Post Evaluation of 2007-2013 RDPs. European Evaluation Network for Rural Development, Brussels: European Commission.

Esteves, A.M., D. Franks and F. Vanclay (2012). Social impact assessment: the state of the art, Impact Assessment and Project Appraisal, 30:1, 34-42, https://doi.org/10.1080/14615517.2012.660356.

European Commission (2013). Design and Commissioning of Counterfactual Impact Evaluations. A Practical Guidance for ESF Managing Authorities. Publications Office of the European Union: Luxembourg.

European Commission (2017a). Better Regulation Guidelines, Commission Staff Working Document. Brussels: European Commission. https://www.emcdda.europa.eu/system/files/attachments/7906/betterregulation-guidelines.pdf.

European Commission (2017b). Directorate-General for Agriculture and Rural Development - Unit C.4 (2017): Guidelines. Evaluation of innovation in rural development programmes 2014-2020. https://enrd.ec.europa.eu/evaluation/publications/evaluation-innovation-ruraldevelopment-programmes-2014-2020_en.

FGUVA (2016). Informe de Evaluación ex-post del Programa de Desarrollo Rural de Castilla y León 2007-2013-Tomo I; Fundación General de la Universidad de Valladolid (FGUVA): Valladolid, Spain. https://www.mapa.gob.es/en/desarrollorural/temas/programas-ue/tomo1_informe_definitivo_cl_tcm38-380374.pdf. 
FitzGerald, J., C. McCarthy, E. Morgenroth and P. O'Connell (eds.) (2003). The Mid-Term Evaluation of the National Development Plan (NDP) and Community Support Framework (CSF) for Ireland, 2000-2006, Policy Research Series No. 50, Dublin: Economic and Social Research Institute.

Flyvbjerg, B., M. Holm, K. Skamris and S.L. Buhl (2003). 'How Common and How Large Are Cost Overruns in Transport Infrastructure Projects?', Transport Reviews, Vol. 23(1): 71-88.

Flyvbjerg, B., in association with COWI (2004). Procedures for Dealing with Optimism Bias in Transport Planning - Guidance Document. London: Department of Transport.

Forfás (2013). Social Enterprise in Ireland: Sectoral Opportunities and Policy Issues. https://enterprise.gov.ie/en/Publications/Publication-

files/Forf\%C3\%A1s/Social-Enterprise-in-Ireland-Sectoral-Opportunities-and-

Policy-Issues.pdf.

Forfás (2014). Evaluation of Enterprise Supports for Research, Development and Innovation. https://enterprise.gov.ie/en/Publications/Publicationfiles/Forf\%C3\%A1s/Evaluation-of-Enterprise-Supports-for-ResearchDevelopment-and-Innovation.pdf.

Frechtling, J.A. (2007). Logic modeling methods in program evaluation, San Francisco: Jossey-Bass.

Gertler, P.J., S. Martinez, P. Premand, L.B. Rawlings and C.M. Vermeersch (2016). Impact Evaluation in Practice, 2nd ed., World Bank Publications: Washington, DC, USA.

Grealis, E. and C. O'Donoghue (2015). The Bio-Economy Input Output Model: Development and Uses; Teagasc Rural Economy Research Centre: Galway, Ireland. https://www. teagasc.ie/media/website/publications/2014/Economic_Impact_of_the_Irish_B ioeconomy.pdf.

Hart K., D. Baldock, P. Weingarten, B. Osterburg, A. Povellato, F. Vanni, C. Pirzio-Biroli and A. Boyes (2011). What tools for the European agricultural policy to encourage the provision of public goods? Study for the European Parliament's Committee on Agriculture and Rural Development. http://www.europarl.europa.eu/studies.

Heinrich, C., A. Maffioli and G. Vazquez (2010). A Primer for Applying Propensity-Score Matching. Inter-American Development Bank: Washington, DC, USA, 2010. https://pdfs.semanticscholar.org/c1af/121ce5a7d52075722b87a5f012da83dc5 502.pdf.

Hirano, K. and G.W. Imbens (2004). 'The propensity score with continuous treatments', in Gelman, A. and X.-L. Meng (Eds.) Applied Bayesian modeling and causal inference from incomplete-data perspectives (pp. 73-84). Chichester: Wiley InterScience.

Hlavsa T., M. Hruska and E. Turkova (2017). 'The impact of investment support from the Rural Development Programme of the Czech Republic for 2007-2013 on the economic efficiency of farms', Studies in Agricultural Economics, 119.

HM Treasury (2020). Magenta Book - Central Government Guidance on Evaluation. https://www.gov.uk/government/publications/the-magenta-book. 
Hudson, B., D. Hunter and S. Peckham (2019). 'Policy failure and the policyimplementation gap: can policy support programs help?', Policy Design and Practice, 2:1, 1-14, doi: https://doi.org/10.1080/25741292.2018.1540378.

Hynes, S. and N. Hanley (2006). 'Preservation versus Development on Irish Rivers: Whitewater Kayaking and Hydro Power in Ireland', Land Use Policy, 23, pp.170-180.

Indecon (2013). Indecon's Evaluation of JobBridge, Department of Social Protection: Dublin.

Indecon (2019). Indecon Mid-Term Evaluation of the Rural Development Programme Ireland (2014-2020). Indecon International Economic Consultants in association with the Countryside and Community Research Institute (University of Gloucestershire): Dublin: Indecon.

Inter-Departmental Group (2015). Our Communities: A Framework Policy for Local and Community Development in Ireland. Dublin: Department of Environment, Community and Local Government.

Jacob, R., P. Zhu, M.A. Somers and H. Bloom (2012). A Practical Guide to Regression Discontinuity. MDRC: New York, NY, USA. https://www.mdrc.org/sites/default/files/RDD\%20Guide_Full\%20rev\%202016_ $0 . p d f$.

Jarmin, R.S. (1999). 'Evaluating the Impact of Manufacturing Extension on Productivity Growth', Journal of Policy Analysis and Management, 18 (1): 99-119.

Kelly, E., S. McGuinness and J. Walsh (2015). An Evaluation of the Back to Education Allowance. ESRI Research Series 47. Dublin: The Economic and Social Research Institute.

Kelly, E., S. McGuinness, P. Redmond, M. Savage and J. Walsh (2019). An initial evaluation of the Effectiveness of Intreo Activation Reforms, ESRI Research Series No. 81. Dublin: The Economic and Social Research Institute.

Khandker, S.R., G.B. Koolwal and H.A. Samad (2009). Handbook on Impact Evaluation: Quantitative Methods and Practices. World Bank Publications: Washington, DC, USA.

Kirchweger S. and J. Kantelhardt (2015). 'The dynamic effects of government-supported farm-investment activities on structural change in Austrian agriculture', Land Use Policy, 48, pp. 73-93.

Kirchweger, S., J. Kantelhardt and F. Leisch (2015). 'Impacts of the government-supported investments on the economic farm performance in Austria', Agricultural Economics - Czech, 8, 343-355.

Laporta, L., H. Martins, R. da Silva Vieira, M. Alves, J. Santos, R. Teixeira, T. Morais, G. Ferreira and R. Godinho (2016). 'Relatório Final da Avaliação Ex-post do Programa de Desenvolvimento Rural do Mainlande 2007-2013 (ProDeR)', in Domingos, T., A. Oliveira das Neves and C. Marta-Pedroso (Eds.), Estudo encomendado pela Autoridade de Gestão do ProDeR; Instituto Superior Técnico, Instituto de Estudos Sociais e Económicos e Instituto Politécnico de Bragança: Bragança, Portugal. 
Learning and Work Institute, The (2016). Scotland's Future Employment Services: Literature Review. Leicester: The Learning and Work Institute.

Lenihan, H. (2011). 'Enterprise policy evaluation: Is there a 'new' way of doing it?', Evaluation and Program Planning, 34 (4), 323-332.

Lenihan, H., M. Hart and S. Roper (2005). 'Developing an evaluative framework for industrial policy in Ireland: fulfilling the audit trail or an aid to policy development', Quarterly Economic Commentary: 69-86.

Lipscomb, C.A., J. Youtie, P. Shapira, S. Arora and A. Krause (2018). 'Evaluating the impact of manufacturing extension services on establishment performance', Economic Development Quarterly, 32(1), 29-43. doi: https://doi.org/10.1177/0891242417744050.

Loi, M. and M. Rodrigues (2012). A Note on the Impact Evaluation of Public Policies: The Counterfactual Analysis. Publications Office of the European Union: Luxembourg, 2012.

http://publications.jrc.ec.europa.eu/repository/bitstream/JRC74778/lbna25519 enn.pdf.

Mack, G., G. Fîntîneru and A. Kohler (2018). 'Do rural development measures improve vitality of rural areas in Romania?', AgroLife Scientific Journal, 7(2), 82-98.

Manton, R., S. Hynes and E. Clifford (2016). 'Greenways as a tourism resource: a study of user spending and value', Tourism Planning and Development, 13(4), 427-448. doi: 10.1080/21568316.2015.1136835.

Maye, D., G. Enticott and R. Naylor (2020). 'Theories of Change in Rural Policy Evaluation', Sociologia Ruralis, 60: 198-221. https://doi.org/10.1111/soru.12269.

Mayne, J. (2015). Useful Theory of Change Models, Canadian Journal of Program Evaluation, 30 (2), 119-142.

Mayne, J. (2017). Theory of change analysis; Building robust theories of change. Canadian Journal of Program Evaluation / La Revue canadienne d'évaluation de programme, 32.2 (Fall / automne ), 155-173 doi: 10.3138/cjpe.31122.

Mayor, K., S. Scott and R.S. Tol (2007). 'Comparing the travel cost method and the contingent valuation method: An application of convergent validity theory to the recreational value of Irish forests'. ESRI Working Paper (No. 190). Dublin: Economic and Social Institute.

McGuinness, S. and M. Hart (2004). 'Mixing the grant cocktail: towards an understanding of the outcomes of financial support to small firms', Environment and Planning C: Government and Policy, 22(6), 841-857.

McGuinness, S., P.J. O'Connell, E. Kelly and J. Walsh (2011). Activation in Ireland: An Evaluation of the National Employment Action Plan. ESRI Research Series No. 20. ISBN978 0707003139.

McGuinness, S., P.J. O'Connell and E. Kelly (2014). 'The Impact of Training Programme Type and Duration on the Employment Chances of the Unemployed in Ireland', The Economic and Social Review, Vol. 45(3), pp.425-450. 
McGuinness, S. and P. Redmond (2018). Estimating the Effect of an Increase in the Minimum Wage on Hours Worked and Employment in Ireland. Economic and Social Research Institute, Dublin.

McGuinness, S., A. Bergin, E. Kelly, S. McCoy, E. Smyth, D. Watson and A. Whelan (2018). Evaluation of PLC Programme Provision. ESRI Research Series 61.

Medonos, T., T. Ratinger, M. Hruška and J. Špička (2012). 'The assessment of the effects of investment support measures of the rural development programmes: The case of the Czech Republic', Agris on-Line Papers in Economics and Informatics, 4(4), $35-48$.

Michalek J. (2012a). Counterfactual impact evaluation of EU rural development programmes-Propensity Score Matching methodology applied to selected EU Member States. Vol. 1: A micro-level approach. Institute for Prospective and Technological Studies, Joint Research Centre.

Michalek J. (2012b). Counterfactual impact evaluation of EU rural development programmes-Propensity Score Matching methodology applied to selected EU Member States. Vol. 2: A regional approach. Institute for Prospective and Technological Studies, Joint Research Centre.

Michalek J. and N. Zarnekow (2012). 'Application of the rural development index to analysis of rural regions in Poland and Slovakia', Social Indicators Research, 105(1), pp. 1-37.

Michalek, J., P. Ciaian and D. Kancs (2014). 'Capitalization of the single payment scheme into land value: Generalized propensity score evidence from the European Union', Land Economics, 90(2), 260-289. doi: 10.3368/le.90.2.260.

Michalek, J., P. Ciaian and D. Kancs (2016). Investment crowding out: Firm-level evidence from northern Germany. 50(9), 1579-1594. doi: 10.1080/00343404.2015.1044957.

Michalek, J., P. Ciaian and J. Pokrivcak (2018). 'The impact of producer organizations on farm performance: The case study of large farms from Slovakia', Food Policy, 75, 80-92. doi: 10.1016/j.foodpol.2017.12.009.

Michalek, J., P. Ciaian and F. Di Marcantonio (2020). 'Regional impacts of the EU Rural Development Programme: Poland's food processing sector', Regional Studies, 1-13.

Midmore P., L. Langstaff, S. Lowman and A. Vaughan (2008). 'Qualitative evaluation of European rural development policy: Evidence from comparative case studies'. Paper presented at the 12th Congress of the European Association of Agricultural Economists. August 26-29, Ghent.

Milstein, B. and T. Chapel (2011). The Community Tool Box: Developing a Logic Model or Theory of Change. Lawrence, KS: University of Kansas. http://ctb.ku.edu/en/tablecontents/sub_section_examples_1877.aspx.

Monsalve, F., J.E. Zafrilla and M.Á. Cadarso (2016). 'Where have all the funds gone? Multiregional input-output analysis of the European Agricultural Fund for Rural Development', Ecological Economics, 129, 62-71.

Morgenroth, E. (2009). 'Irish Public Capital Spending in Recession', ESRI Working Paper No. 298. Dublin: Economic and Social Research Institute. 
Morgenroth, E. (2011). 'Infrastructure', in Quarterly Economic Commentary (Summer). Dublin: Economic and Social Research Institute.

Morgenroth, E. (2014). Submission to the Department of Public Expenditure and Reform on the Review of the Public Capital Programme.

Motherway, B. (2006). The role of community development in tackling poverty in Ireland, Dublin: Combat Poverty Agency. www.combatpoverty.ie/publications/TheRoleOfCommunityDevelopmentLiteratureReview_2006.pdf. Accessed 11 August 2020.

O'Connell, P.J., S. McGuinness and E. Kelly (2012). 'The transition from short-to long-term unemployment: A statistical profiling model for Ireland', The Economic and Social Review, 43(1, Spring), 135-164.

OECD (1991). The DAC Principles for the Evaluation of Development Assistance. https://www.oecd.org/development/evaluation/2755284.pdf.

OECD (2019). Better Criteria for Better Evaluation - Revised Evaluation Criteria Definitions and Principles for Use, OECD/DAC Network on Development Evaluation. https://www.oecd.org/dac/evaluation/revised-evaluation-criteria-dec2019.pdf.

Ordowich, C., D. Cheney, J. Youtie, A. Fernandez Ribas and P. Shapira (2012). Evaluating the Impact of MEP Services on Establishment Performance: A Preliminary Empirical Investigation. U.S. Census Bureau Center for Economic Studies Paper No. CES-WP-12-15.

Papadopoulou, E., C. Papalexiou and N. Hasanagas (2012). 'Participatory evaluation of rural development programmes: a qualitative approach in the case of modernisation of agricultural holdings in Greece', Regional Science Inquiry Journal, 4(1), 81-94.

Patton, M.Q. (2008). Utilization-focused evaluation (4th ed.). Thousand Oaks, CA: Sage.

Petrick M. and P. Zier (2011). 'Regional employment impacts of Common Agricultural Policy measures in Eastern Germany: A difference-in-differences approach', Agricultural Economics, 42(2), pp. 183-193.

Pritchard, D. and A. Kazimirski (2014). Building your measurement framework: NPC's four pillar approach. London: New Philanthropy Capital. www.thinknpc.org/wpcontent/uploads/2015/04/NPCs-four-pillars-summary.pdf.

Psaltopoulos D., E. Balamou, D. Skuras, T. Ratinger and S. Sieber (2011). 'Modelling the impacts of CAP Pillar 1 and 2 measures on local economies in Europe: Testing a case study-based CGE-model approach', Journal of Policy Modeling, 33 (1), pp. 53-69.

PwC (2019). New Children's Hospital Independent Review 2019. Dublin: PricewaterhouseCoopers. https://merrionstreet.ie/MerrionStreet/en/NewsRoom/Releases/20190409_NC H_Report.pdf.

Redmond, P. and J. Regan (2015). 'Incumbency advantage in a proportional electoral system: a regression discontinuity analysis of Irish elections', European Journal of Political Economy, 38, 244-256. 
Rogers, P. (2014). Theory of Change, Methodological Briefs: Impact Evaluation 2. UNICEF Office of Research, Florence https://www.unicef-irc.org/publications/747theory-of-change-methodological-briefs-impact-evaluation-no-2.html.

Roper, S. and N. Hewitt-Dundas (2001). 'Grant assistance and small firm development in Northern Ireland and the Republic of Ireland', Scottish Journal of Political Economy, 48(1), 99-117.

Schroeder, L.A., A. Gocht and W. Britz (2015). 'The impact of pillar II funding: Validation from a modelling and evaluation perspective', Journal of Agricultural Economics, $66,415-441$.

Stern, E. (2015). Impact Evaluation: A Guide for Commissioners and Managers. Bond. https://www.bond.org.uk/sites/default/files/resourcedocuments/impact_evalu ation_guide_0515.pdf.

Storey, D.J. and B.S. Tether (1998). 'Public policy measures to support new technologybased firms in the European Union', Research policy, 26(9), 1037-1057.

Storey, D.J. (2000). Six steps to heaven. Handbook of Entrepreneurship, Blackwells: Oxford.

Storey, D.J. (2003). 'Entrepreneurship, small and medium sized enterprises and public policies', in Handbook of entrepreneurship research (pp. 473-511). Springer, Boston, MA.

Tyrvainen, L. and A. Miettinen (2000). 'Property Prices and Urban Forest Amenities', Journal of Environmental Economics and Management 39 (2): 205-223.

University of Kansas' Work Group for Community Health and Development (1994). The Community Toolbox: Bringing solutions to light. ctb.ku.edu/en/default.aspx.

Ustaoglu, E., B. Williams and E. Murphy (2016). 'Integrating CBA and land-use development scenarios: Evaluation of planned rail investments in the Greater Dublin Area, Ireland', Case Studies on Transport Policy, 4(2), 104-121.

Whelan, A., S. McGuinness and J. Delaney (2019). Valuing Community Development through the Social Inclusion Programme (SICAP) 2015-2017: Towards a Framework for Evaluation. Research Series No. 77, Dublin: The Economic and Social Research Institute.

Whelan, A., J. Delaney, S. McGuinness and E. Smyth (2020). Evaluation of SICAP Pre-Employment Supports. Dublin: The Economic and Social Research Institute. 


\section{APPENDIX A}

\section{TABLE A.1 LOGIC MODEL EXAMPLE FOR SICAP (GOAL 1)}

\begin{tabular}{|c|c|c|c|c|}
\hline Inputs & Activities & Outputs & Outcomes/Impacts & Programme indicators \\
\hline $\begin{array}{l}\text { What resources go into a } \\
\text { programme? }\end{array}$ & $\begin{array}{l}\text { What activities does the } \\
\text { programme undertake? }\end{array}$ & $\begin{array}{l}\text { What is produced through those } \\
\text { activities? (Short-run) }\end{array}$ & $\begin{array}{l}\text { What are the changes/benefits that result from } \\
\text { the programme? (Long-run) }\end{array}$ & Quantitative measures \\
\hline $\begin{array}{l}\text { Human resources (time } \\
\text { invested by staff, } \\
\text { volunteers, partners and } \\
\text { local people) }\end{array}$ & $\begin{array}{l}\text { Intervention(s) by SICAP to help LCG } \\
\text { members to gain knowledge and } \\
\text { skills (capacity-building) }\end{array}$ & $\begin{array}{l}\text { Increased share of individuals within the } \\
\text { local community involved in LCGs } \\
\text { (particularly the hardest to reach in the } \\
\text { most disadvantaged areas) }\end{array}$ & $\begin{array}{l}\text { Increased engagement of local community } \\
\text { members (particularly, the hardest to reach in the } \\
\text { most disadvantaged areas) }\end{array}$ & $\begin{array}{l}\text { No. of LCGs assisted under SICAP in Goal } 1 \\
\text { (including level of intensity); no. of members } \\
\text { assisted by the LCGs; no. of target groups } \\
\text { represented in LCGs }\end{array}$ \\
\hline $\begin{array}{l}\text { Financial resources (SICAP } \\
\text { funding, grants, donations } \\
\text { and user fees) }\end{array}$ & $\begin{array}{l}\text { Intervention(s) by SICAP to } \\
\text { determine the LCG's aims and goals } \\
\text { and develop a strategic plan for the } \\
\text { LCG }\end{array}$ & $\begin{array}{l}\text { Increased engagement of SICAP staff } \\
\text { with local community members } \\
\text { (particularly the hardest to reach in the } \\
\text { most disadvantaged areas) }\end{array}$ & $\begin{array}{l}\text { Increased links between LCGs, local service } \\
\text { providers or other statutory and key providers }\end{array}$ & $\begin{array}{l}\text { No. of LCGs collaborating with other LCGs, } \\
\text { local service providers or other statutory and } \\
\text { key providers }\end{array}$ \\
\hline Facilities and equipment & $\begin{array}{l}\text { Intervention(s) by SICAP to assist the } \\
\text { LCG to promote engagement }\end{array}$ & $\begin{array}{l}\text { SICAP target groups have greater } \\
\text { representation and participation in } \\
\text { decision-making structures at a local, } \\
\text { regional and national level }\end{array}$ & $\begin{array}{l}\text { Increased participation in local, regional and/or } \\
\text { national decision-making structures; greater } \\
\text { citizen engagement in line with national policy }\end{array}$ & $\begin{array}{l}\text { No. of LCGs whose members have been } \\
\text { assisted by SICAP to participate in local, } \\
\text { regional or national decision-making } \\
\text { structures (including level of intensity) }\end{array}$ \\
\hline $\begin{array}{l}\text { Knowledge and skills base } \\
\text { (community workers, other } \\
\text { staff and members of LCGs) }\end{array}$ & $\begin{array}{l}\text { Intervention(s) by SICAP to assist the } \\
\text { LCG to implement its strategic plan }\end{array}$ & $\begin{array}{l}\text { Strengthened LCGs and local } \\
\text { communities }\end{array}$ & $\begin{array}{l}\text { LCGs have greater capacity to address the needs } \\
\text { of the disadvantaged communities they represent }\end{array}$ & $\begin{array}{l}\text { Progression matrix as suitable for some LCGs; } \\
\text { no. of LCGs assisted by SICAP to leverage } \\
\text { funding (amount of funding) }\end{array}$ \\
\hline $\begin{array}{l}\text { Research base (internal and } \\
\text { external) }\end{array}$ & $\begin{array}{l}\text { Intervention(s) by SICAP to assist the } \\
\text { LCG to participate in local, regional } \\
\text { and national activities }\end{array}$ & $\begin{array}{l}\text { Improvements in the well-being of local } \\
\text { persons through increased resources, } \\
\text { facilities, services, etc. brought about by } \\
\text { active engagement of citizens }\end{array}$ & $\begin{array}{l}\text { Increased uptake of mainstream services by } \\
\text { disadvantaged individuals; improved economic } \\
\text { conditions (increased income, increased financial } \\
\text { stability and/or reduced economic inequality) }\end{array}$ & $\begin{array}{l}\text { Increased contacts with social services; } \\
\text { percentage of people in poverty and/or with } \\
\text { high deprivation levels; mean and median } \\
\text { income; share of unemployed individuals }\end{array}$ \\
\hline \multirow[t]{3}{*}{$\begin{array}{l}\text { Involvement of } \\
\text { collaborators (local, state, } \\
\text { national agencies and other } \\
\text { organisations) }\end{array}$} & $\begin{array}{l}\text { Intervention(s) by SICAP to connect } \\
\text { individuals or LCGs to advocate for } \\
\text { their interests. Increased interagency } \\
\text { responses to local needs }\end{array}$ & $\begin{array}{l}\text { Increased individual, organisational and } \\
\text { community capacity and higher } \\
\text { engagement by service providers in local } \\
\text { communities }\end{array}$ & $\begin{array}{l}\text { Improved social conditions (reduced crime and } \\
\text { violence; improved co-operation and social } \\
\text { connectedness) }\end{array}$ & $\begin{array}{l}\text { Frequency of meetings for LCGs; presence of } \\
\text { support networks; no. of LCGs collaborating } \\
\text { with other LCGs, local service providers or } \\
\text { other statutory and key provider; crime rates }\end{array}$ \\
\hline & $\begin{array}{l}\text { Intervention(s) by SICAP to assist the } \\
\text { LCG to monitor and evaluate its } \\
\text { progress }\end{array}$ & $\begin{array}{l}\text { Improved communication among diverse } \\
\text { individuals and groups in the population }\end{array}$ & $\begin{array}{l}\text { Increased networks; greater sense of collective } \\
\text { efficacy; greater respect for the individual and for } \\
\text { diversity, equality and cultural difference }\end{array}$ & $\begin{array}{l}\text { Share of individuals within the local } \\
\text { community involved in LCGs; share of } \\
\text { individuals from target groups involved in } \\
\text { LCGs in the local community }\end{array}$ \\
\hline & $\begin{array}{l}\text { NOTE: Intervention type (one-to-one } \\
\text { meeting, group meeting, workshop, } \\
\text { information session, etc.) and } \\
\text { duration can be recorded }\end{array}$ & $\begin{array}{l}\text { Increased level of satisfaction expressed } \\
\text { by the participants in the programme }\end{array}$ & Greater participation in democratic processes & $\begin{array}{l}\text { Share of individuals registered and } \\
\text { participating in local and national elections; } \\
\text { share of target groups participating in key } \\
\text { institutions, organisations or boards }\end{array}$ \\
\hline
\end{tabular}

Source: Whelan et al. (2019) 


\section{APPENDIX B}

\section{Econometric approaches to the evaluation of rural development programmes}

\section{B1.1 Matching techniques}

Propensity score matching (PSM) is a technique that is often used to measure the impact of an intervention, and its principal advantage is that it helps insulate the estimated impacts against potential selection bias. The impact of a policy intervention is generally estimated by comparing the final outcomes of the treatment and control groups, with any differences being assigned as the impacts of the policy intervention. The problem with this approach is that there may exist fundamental differences in the observable characteristics of the control and the treatment group that are related to the outcome variable, which can lead to biased estimates. For instance, take any attempt to measure the impact of training programme on worker productivity; if it is the case that those workers receiving training tended to have more experience and higher levels of schooling, compared to those workers in the control group, the estimates of training are likely to be biased. Treatment group members' higher observed productivity is likely to be a combination of training and the fact that they are also more educated and have higher levels of experience; thus a standard econometric model that does not properly control for important differences in observable characteristics of the control and treatment group may not be sufficient to isolate the impacts of training on productivity.

Selection bias will typically arise from one of two effects; firstly where the programme implementor selects individuals for the programme most likely to succeed in it, referred to as 'picking winners' ${ }^{25}$ secondly, selection bias may be due to 'self-selection', whereby individuals with superior characteristics are more likely to volunteer for programmes. ${ }^{26}$ Selection bias can also be simultaneously driven by a combination of 'picking winners' and 'self-selection'. PSM techniques seek to overcome the selection bias problem by ensuring that each member of the treatment group is matched with a control group member with identical observable characteristics. ${ }^{27}$ Given that the PSM approach eradicates any differences in observable characteristics between the control and treatment group, researchers can be more confident that any differences in outcomes ${ }^{28}$ can

25 Taking the training example again, the programme implementor selects workers with higher levels of schooling and tenure for training.

26 For instance, the training programme may be available to all workers but those with more education and experience are much more likely to volunteer.

27 Taking our training example, each treatment group member will be matched with a control group individual with the same levels of education and experience. 
be attributed to the impacts of the policy intervention being measured. PSM methods are most suitable where a control and treatment group are identifiable in cross-sectional data. ${ }^{29}$ See McGuinness et al. (2018) for an application using Irish data.

\section{B1.2 Regression Discontinuity Design (RDD)}

Regression Discontinuity Design (RDD) is another technique used to estimate the impact of a policy intervention and the approach has the advantage of being able to isolate the counterfactual by measuring the difference in intervention outcomes between treatment and control populations with very similar characteristics. As such, the methodology eliminates any biases associated with sample selection. RDD methods are usually employed in instances where a policy intervention is implemented at a fixed threshold within a given distribution. The method compares the outcome of programme beneficiaries and non-beneficiaries around a cut-off point determined by a programme/measure accessibility criterion. Participants around the cut-off in both groups are deemed comparable and causal impacts can be estimated (Jacob et al., 2012). An example of a policy intervention where RDD would be suitable might be the impact of a scholarship on student performance, where the scholarship is awarded on the basis of set threshold criteria. For example, the student obtaining 80 per cent or over in a particular examination. The rationale for the approach is that bare winners (those students gaining 80 per cent in their exam) and bare losers (those students gaining 79 per cent in the exam) will be very similar in all respects and that comparing their outcomes will allow us to isolate the causal impact of the policy intervention (in this instance scholarships). The RDD approach is most suitable for policy interventions that are implemented at a particular threshold and where there is sufficient sample size of individuals immediately either side of the threshold. See Redmond and Regan (2015) for an application using Irish data.

\section{B1.3 Difference-in-Differences (DiD)}

The DiD allows a comparison between the outcomes of beneficiaries and non-beneficiaries (first difference). The approach is typically used in circumstances where an intervention is implemented at a particular in time, allowing outcomes to be compared before and after the policy intervention. The approach will again typically involve control and treatment groups and is quite powerful in the sense that it can eradicate biases associated with unobserved heterogeneity (that are time invariant). Unobserved heterogeneity bias relates to factors that, while not observed directly in the data, differ systematically between the control and treatment groups in a way that is also correlated with the outcome variable. Going back to our earlier example of training for example, the treatment group may have 
higher levels of motivation and ability, neither of which is observed in the data, however these variables will also be influencing productivity. Thus, even if we are able to control for differences in observables between the treatment and control groups, ${ }^{30}$ the estimated training impact may still be biased due to failure to control for these unobservable factors. A recent example of the technique in an Irish context was a study examining the impact of the 2016 minimum wage change on hours worked (McGuinness and Redmond, 2018); the authors compared the differences in levels of hours worked between the treatment and control groups both before and after the rate rise and took the difference between these as a measure of the policy change. ${ }^{31}$ The DiD approach can be combined with matching techniques to ensure that both unobserved heterogeneity and selection biases are addressed. This approach is referred to as Conditional DiD. Michalek (2012) reviews the suitability of PSM-DiD in assessing regional programme impacts at a micro and regional level. DiD methodology is typically implemented where data exist for both control and treatment groups over a time period during which a policy intervention was implemented.

\section{B1.4 Instrumental Variables (IV)}

The Instrumental Variables (IV) technique is adopted when there are concerns regarding the endogeneity of the policy variable. Endogeneity concerns generally relate to unobserved heterogeneity bias discussed above; however, the term also encompasses simultaneity bias whereby the outcome and policy variables simultaneously influence each other. However, from an evaluation perspective our greatest concern will tend to be unobserved heterogeneity bias. ${ }^{32}$ Another example of this bias that is often cited in the literature, as a justification for IV, is the study of the impact of schooling on earnings. Innate ability, which is typically unobserved, will simultaneously impact both schooling levels and earnings and the failure to control for it will lead to biased results. However, if we are able to find an exogenous instrument that explains the policy intervention and is not correlated with outcome, then we can use this to implement IV and generate unbiased estimates of the policy intervention. A highly cited example of the IV approach is that of Card (1993) who, when examining the relationship between schooling and earnings used distance to college as an instrument, on the basis that this would explain the level of schooling accumulated but would also be independent of earnings. The IV approach is generally adopted when we are concerned about unobserved heterogeneity bias but have an independent instrument available to us. IV is usually estimated in cross-sectional datasets and requires a series of postestimation checks to be carried out in order to demonstrate the validity of the chosen instrument. Within the rural development literature, using an external

$30 \quad$ Using PSM for instance.

31 Thus, they compared the pre-2016 difference with the post-2016 difference in hours worked between the treatment and control groups; the difference in the differences was taken as a measure of the policy change. 
instrument has also been used to approximate the randomisation of programme participation. For example, a delay in programme implementation in some areas compared to others. In this case, causal effects can be estimated in under certain conditions (Khandker et al., 2009).

Table B.1 summarises each of these methodological approaches along with the types of bias that these techniques can address and the associated data requirements.

TABLE B.1 OVERVIEW OF THE METHODOLOGICAL APPROACHES, TYPES OF BIAS ADDRESSED AND DATA REQUIREMENTS

\begin{tabular}{|c|c|c|}
\hline Methodological Approach & Type of Bias Addressed & Data Requirements \\
\hline Propensity Score Matching (PSM) & Selection Bias & $\begin{array}{l}\text { Cross-sectional data for Treatment } \\
\text { and Control Groups }\end{array}$ \\
\hline $\begin{array}{l}\text { Regression Discontinuity Design } \\
\text { (RDD) }\end{array}$ & $\begin{array}{l}\text { Selection Bias, } \\
\text { Unobserved Heterogeneity }\end{array}$ & $\begin{array}{l}\text { Longitudinal Data for Treatment and } \\
\text { Control Groups, Cross-sectional data } \\
\text { for Treatment and Control Groups }\end{array}$ \\
\hline Difference-in-Differences (DiD) & Unobserved Heterogeneity & $\begin{array}{l}\text { Longitudinal Data for Treatment and } \\
\text { Control Groups }\end{array}$ \\
\hline $\begin{array}{l}\text { Conditional Difference-in- } \\
\text { Differences (PSM-DiD) }\end{array}$ & $\begin{array}{l}\text { Selection Bias, } \\
\text { Unobserved Heterogeneity }\end{array}$ & $\begin{array}{l}\text { Longitudinal Data for Treatment and } \\
\text { Control Groups }\end{array}$ \\
\hline Instrumental Variables (IV) & $\begin{array}{l}\text { Endogeneity, } \\
\text { Reverse Causality, } \\
\text { Unobserved Heterogeneity }\end{array}$ & $\begin{array}{l}\text { Cross-sectional data for Treatment } \\
\text { and Control Groups, and an } \\
\text { appropriate instrumental variable }\end{array}$ \\
\hline
\end{tabular}


Whitaker Square,

Sir John Rogerson's Quay,

Dublin 2

Telephone +35318632000

Email admin@esri.ie

Web www.esri.ie

Twitter @ESRIDublin 